\title{
əTwo Types of Mid-High-Latitude Low-Frequency Intraseasonal Oscillations near the Ural Mountains during Boreal Summer
}

\author{
TAO ZHU ${ }^{\mathrm{a}}$ AND JING YANG ${ }^{\mathrm{a}, \mathrm{b}}$ \\ ${ }^{a}$ State Key Laboratory of Earth Surface Processes and Resource Ecology/Key Laboratory of Environmental Change and Natural \\ Disaster, Faculty of Geographical Science, Beijing Normal University, Beijing, China \\ ${ }^{\mathrm{b}}$ Southern Marine Science and Engineering Guangdong Laboratory, Guangzhou, China
}

(Manuscript received 25 July 2020, in final form 8 February 2021)

\begin{abstract}
Two types of mid-high-latitude low-frequency intraseasonal oscillations (LF-ISOs), featuring eastward and westward propagation, have been identified over the Eurasian continent in the past 37 summers (1982-2018). The eastward and westward propagating modes commonly have a dominant periodicity of 30-50 days near the Ural Mountains (UM) but have different origins and evolutions. The eastward propagating LF-ISO initiates over eastern North America, migrates northeastward across northeastern North America-western North Atlantic, central North Atlantic, western Europe, and the UM, then propagates southeastward to northwestern and eastern China, which is the Atlantic-Eurasian continental mode. In contrast, the westward propagating mode is quasicircumpolar, initiating over the East Siberian Sea and moving southwestward across the UM and northern Europe and eventually reaching Greenland and the Canadian Arctic Archipelago. These two mid-high-latitude LF-ISOs are accompanied by significant tropical intraseasonal variations with evident tropical-extratropical interactions. Meanwhile, these two LF-ISOs have different decadal preferences before and after 2000, which are ascribed to the decadal change of both intraseasonal efficient kinetic energy obtained from the mean flow over their genesis region and their background flow associated with the North Atlantic Oscillation/Arctic Oscillation decadal change. This study deepens the understanding of subseasonal variations for mid-high latitudes and subseasonal prediction sources for low-latitude regions.
\end{abstract}

KEYWORD: Intraseasonal variability

\section{Introduction}

Tropical intraseasonal oscillation (ISO) significantly affects both local and global subseasonal-to-seasonal atmospheric variations (e.g., Wheeler et al. 2009; Zhang 2013; RecaldeCoronel et al. 2020) and even causes extreme weather (e.g., Jones et al. 2004; Xavier et al. 2020) and climate events (e.g., Lau and Chan 1986; Batstone and Hendon 2005; Lybarger and Stan 2019; Cui et al. 2020). It mainly features a periodicity of 30-60 days and eastward/northeastward propagation during boreal winter/summer (Madden and Julian 1971, 1972; Sperber 2003). The Madden-Julian oscillation (MJO; Wheeler and Hendon 2004) and boreal summer ISO (Lee et al. 2013) usually serve as important indices for low-latitude regional operational subseasonal monitoring and prediction (https://cmdp.ncc-cma.net/pred/ cn_bsiso.php; https://www.cpc.ncep.noaa.gov/products/precip/ CWlink/MJO/whindex.shtml).

Like tropical ISO, mid-high-latitude ISO is comparably crucial for regional subseasonal variations, and can frequently trigger flooding (e.g., Chan et al. 2002; Yang et al. 2013; Liu et al. 2014) and heatwaves (e.g., Teng et al. 2013; Gao et al. 2017; Qi et al. 2019) in both extratropical (e.g., Krishnamurti and Gadgil 1985; Ferranti et al. 1990; Watanabe and Yamazaki 2014; Yang et al. 2019) and tropical regions (e.g., Stan et al. 2017; Yang and Wu 2019). Recent studies have reported that the subseasonal dynamical prediction biases in

¿ Denotes content that is immediately available upon publication as open access.

Corresponding author: Jing Yang, yangjing@bnu.edu.cn
East Asian region primarily come from mid-high-latitude ISO (Qi and Yang 2019; Liu et al. 2020). However, mid-high-latitude ISO is more regionally diverse in periodicity and propagation (e.g., Li 1991; Kikuchi and Wang 2009; Yang et al. 2012) and has not been as well recognized as a unified framework of tropical ISO, and thus lacks well-constructed indices for regional subseasonal prediction. Previous studies on mid-high-latitude ISO mainly concentrated on high-frequency (fewer than 30 days) periodicity (e.g., Nitta 1983; Yamada and Uyeda 2006; Yang et al. 2010, 2014). Fujinami and Yasunari (2004), for example, found that the mid-high-latitude wave train with eastward propagation along the westerly jet during the summer, with periodicity of 7-20 days, originated from the northeastern Atlantic (e.g., Simmons et al. 1983; Ding and Wang 2007; Yang et al. 2010; Hu et al. 2016). This quasi-biweekly mid-high-latitude wave train has been well identified in many previous studies (Ding and Wang 2007; Gao et al. 2017; Yang et al. 2017).

However, the mid-high-latitude low-frequency ISO (LF-ISO), with more than 30-day periodicity, is still poorly understood, although it has been detected in several previous studies. Based on the Global Atmospheric Research Program's (GARP) First Global Experiment (FGGE) data, Krishnamurti and Gadgil (1985) found a strong ISO signal with a periodicity of 30-50 days near the mid-highlatitude westerly jet exit. Since then, several studies have reported their findings of LF-ISO in mid-high latitudes, but they do not reach agreement regarding propagation and origins (e.g., Branstator 1987; Li 1991; Dickey et al. 1991). In terms of propagation, Ghil and Mo (1991), for example, found a Northern Hemisphere mid-highlatitude ISO with periodicity of 40-50 days that exhibited both westward-traveling and standing components in the 700-hPa geopotential height; He and Yang (1992) proposed a roughly 40-day mid-high-latitude ISO over East Asia featuring an eastward 
propagation; Yang and Li (2003) considered that the mid-highlatitude LF-ISO of meridional wind propagated southward. With regard to origins, the sources of the mid-high-latitude LF-ISO are linked variously with tropical forcing (Lau and Phillips 1986; Chen and Yen 1991; Kawamura et al. 1996), local air-sea interactions (Wang et al. 2013), topography effects (Jin and Ghil 1990; Lott et al. 2001, 2004), and wave-flow interactions (Yang and Cao 1995). The characteristics and origins of mid-high-latitude LF-ISO need to be further clarified.

Mid-high-latitude LF-ISO influences the subseasonal variations and prediction of East Asian weather/climate-for example, the mid-high-latitude LF-ISO of meridional wind perturbations causes the subseasonal variations of summer precipitation in the Changjiang-Huaihe River Basin (Yang and Li 2003), and the LF-ISO of the East Asian westerly jet can regulate the frequency of tropical cyclones and the location of their landfall in mainland China (Qian et al. 2018). Moreover, a recent study has constructed a statistical subseasonal prediction model based on LF-ISO signals from both tropical and mid-high-latitude regions (Zhu and Li 2018), which has exhibited promising prediction skill. One noticeable finding is that a southeastward propagating 30-80-day signal and a southwestward propagating 30-80-day signal over the Eurasian continent serve as two important subseasonal prediction sources of East Asian surface air temperature, but the associated sources of these two signals are not given.

To deepen the understanding of East Asian subseasonal prediction sources, this study aims to investigate the occurrence, dominant behaviors, and origins of mid-high-latitude LF-ISO over the Eurasian continental regions. The remainder of this paper is organized as follows. Section 2 describes the datasets and method. The core region and dominant periodicity of LF-ISO over the Eurasian continent are given in section 3. Section 4 characterizes two types of mid-high-latitude LF-ISOs. A comprehensive discussion for their origins, decadal preferences, and tropical-extratropical interactions is given in section 5 and section 6 gives a summary and implication of this work.

\section{Datasets and method}

\section{a. Datasets}

Daily meteorological fields were retrieved from ERA-Interim provided by the European Centre for Medium-Range Weather Forecasts (ECMWF) (Simmons et al. 2006). The horizontal resolution is $1.5^{\circ} \times 1.5^{\circ}$. The historical record is the period between 1982 and 2018. The meteorological variables include geopotential height (GHT) and winds ( $u$ and $v$ ) at 12 pressure levels (1000, 925, $850,700,600,500,400,300,250,200,150$, and $100 \mathrm{hPa})$. The streamfunction $\psi$ is calculated using $u$ and $v$ through $\nabla^{2} \psi=$ $\partial v / \partial x-\partial u / \partial y$, and the potential function $\chi$ is calculated through $\nabla^{2} \chi=\partial u / \partial x-\partial v / \partial y$. The daily Advanced Very High Resolution Radiometer (AVHRR) outgoing longwave radiation (OLR) with $2.5^{\circ}$ horizontal resolution data were retrieved from the National Oceanic and Atmospheric Administration (NOAA) polar orbiting satellites (Liebmann and Smith 1996). To verify the robustness of the major findings, we also use the circulation data from the National Centers for Environmental Prediction-National Center for Atmospheric Research (NCEP-NCAR) reanalysis dataset (Kalnay et al. 1996) and the results remain similar.

\section{b. Method}

To extract the intraseasonal component, both the annual cycle and synoptic fluctuations have been removed from the raw time series before spectrum analysis and band filtering, as described in many previous studies (e.g., Ding and Wang 2007; Yang and Li 2016). Next, a power spectral analysis using fast Fourier transform (FFT) with a tapered window (Bingham et al. 1967) is applied to the processed time series for each grid or domain average. This time series cover 37 consecutive boreal summers with a total of 6808 days $(37 \times 184=6808)$ from 1982 to 2018 . Here the boreal summer is defined as the time period from 1 May to 31 October (MJJASO). The effective degree of freedom is estimated based on Bretherton et al. (1999). The choice of dominant periodicity is also verified by other spectrum analysis including wavelet analysis (Torrence and Compo 1998) and multiyear averaged peak spectrum (e.g., Yang et al. 2010; Gao et al. 2017). According to the main periodicity band determined in section 3 , we apply a band (here 30-50 days) filter method based on Fourier harmonic analysis (Bloomfield 2000) to extract a specific intraseasonal band (here 30-50 days) of each meteorological variable.

Phase composite analysis is applied to specific variables to identify the spatial structures and temporal evolutions of the ISO (e.g., Fujinami and Yasunari 2004; Mao and Chan 2005). To perform a composite analysis of the significant ISO events, we separate each cycle of the selected ISO events into eight phases. Phases 1 and 5 are the extreme (peak or valley) phases. Phases 3 and 7 are the transition phases. Phases 2, 4, 6, and 8 are located at half of maximum or minimum value (Yang et al. 2014).

To quantitatively measure the propagating speed and direction, we calculate the propagating vector based on a local leadlag correlation method developed by Lau and Lau (1990). For a given grid, the ISO field at this grid point is regarded as a reference time series. A lead-lag correlation is calculated between the time series of each surrounding grid point and the time series at the reference point, from day -5 to day +5 . The magnitude of the propagating speed is estimated by dividing the distance of the line segment by the time interval (i.e., 10 days).

To illustrate the wave energy propagation and accumulation, we consider the wave activity flux (WAF), which was originally formulated by Takaya and Nakamura (2001) and purposely developed by Yang and Li (2016) for the intraseasonal wave train. The WAF can be computed as

$$
W=\frac{1}{|U|}\left[\begin{array}{l}
\bar{u}\left(\psi_{x}^{\prime 2}-\psi^{\prime} \psi_{x x}^{\prime}\right)+\bar{v}\left(\psi_{x}^{\prime} \psi_{y}^{\prime}-\psi^{\prime} \psi_{x y}^{\prime}\right) \\
\bar{u}\left(\psi_{x}^{\prime} \psi_{y}^{\prime}-\psi^{\prime} \psi_{x y}^{\prime}\right)+\bar{v}\left(\psi_{x}^{\prime 2}-\psi^{\prime} \psi_{y y}^{\prime}\right)
\end{array}\right],
$$

where $W$ represents the horizontal WAF, $U$ is the wind velocity, $u$ and $v$ are the zonal and meridional winds respectively, $\psi$ denotes the streamfunction, and a bar and a prime are the low-frequency background state component and intraseasonal component, respectively.

To investigate the source of the Rossby wave train, we calculate the Rossby wave source (RWS; Sardeshmukh and Hoskins 1988), which has been widely used in the study of ISO (Seo and Lee 2017; Tseng et al. 2019; Cui et al. 2020). The RWS can be computed as 

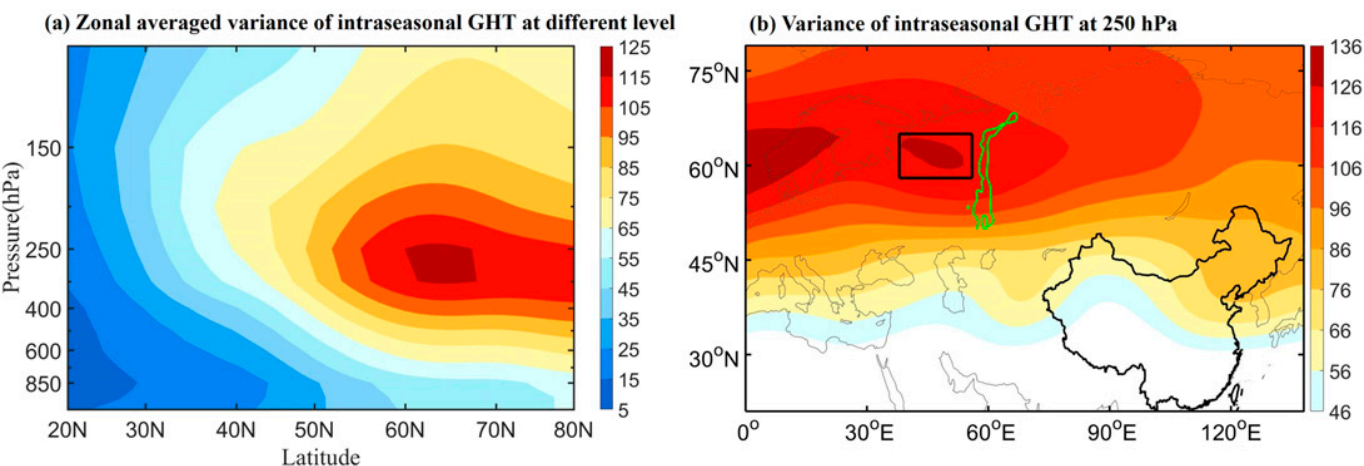

FIG. 1. (a) Zonal averaged $\left(0^{\circ}-138^{\circ} \mathrm{E}\right)$ variance (shading; $\left.\mathrm{gpm}^{2}\right)$ of intraseasonal geopotential height $(\mathrm{GHT})$ in different pressure levels over the Eurasian continent during May-October (MJJASO). (b) Variance of intraseasonal GHT at $250 \mathrm{hPa}\left(\mathrm{GHT} 250\right.$; shading; $\mathrm{gpm}^{2}$ ). The green line in (b) represents the Ural Mountains (UM), and the black rectangle is the selected core region over the mid-high-latitude Eurasian continent.

$$
S=-\nabla_{H} \cdot\left\{\left[U^{\prime}\right]_{\chi}(f+\bar{\zeta})\right\}-\nabla_{H} \cdot\left(\bar{U}_{\chi} \zeta^{\prime}\right),
$$

where $S$ represents the horizontal RWS, $\zeta$ is the relative vorticity, and $f$ is the Coriolis parameter; $\nabla_{H}$ is the horizontal gradient and subscript $\chi$ represents a divergent component. A bar and a prime are the climatological mean and low-frequency intraseasonal component, respectively.

To examine barotropic kinetic energy conversion between the mean flow and the intraseasonal perturbation, we apply the barotropic kinetic energy conversion equation derived by Hoskins et al. (1983), and the energy conversion terms include the following components:

$$
\overline{\overline{\text { CKiso }}}=\frac{\overline{\overline{v^{\prime 2}-u^{\prime 2}}}}{2} \frac{\partial \overline{\bar{u}}}{\partial x}-\frac{\overline{\overline{v^{\prime 2}-u^{\prime 2}}}}{2} \frac{\partial \overline{\bar{v}}}{\partial \mathrm{y}}-\overline{\overline{u^{\prime} v^{\prime}}} \frac{\partial \overline{\bar{u}}}{\partial y}-\overline{\overline{u^{\prime} v^{\prime}}} \frac{\partial \overline{\bar{v}}}{\partial x},
$$

where a double overbar denotes the summer mean state, and a prime is the intraseasonal perturbation. A positive value of CKiso represents energy conversion from the mean flow to the intraseasonal perturbation.

(a) Spectral analysis

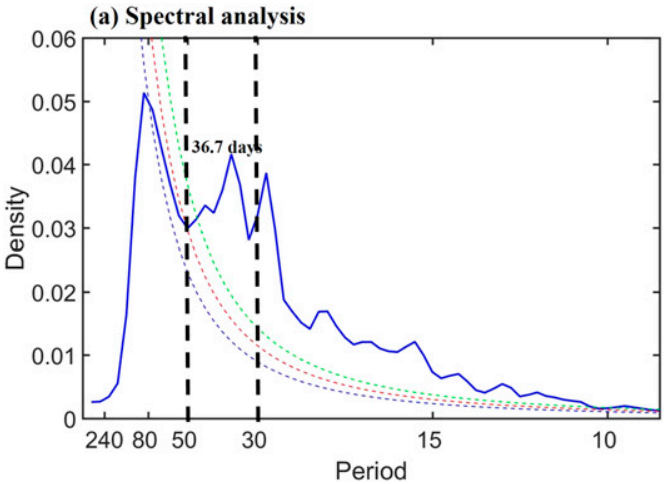

We also carry out a lead-lag regression analysis and an empirical orthogonal function (EOF) to verify the results from the phase composite analysis. Given that the major results of the phase composite, lead-lag regression, and EOF analysis are similar, we show only the results from the phase composite analysis here. These composite results are compared with the whole boreal summer for significance estimation, using the Student's $t$ test and significance level of $95 \%$, as introduced in Bretherton et al. (1999).

\section{Core region and dominant periodicity of LF-ISO over the Eurasian continent during boreal summer}

To find the core region of mid-high-latitude ISO over the Eurasian continent during boreal summer, we calculate the variance of intraseasonal GHT in both horizontal and vertical dimensions. Figure 1a shows the vertical distribution along latitudes for the Eurasian zonal averaged $\left(0^{\circ}-138^{\circ} \mathrm{E}\right)$ variance of intraseasonal circulation (here GHT). The results show that the maximum center locates around altitude $250 \mathrm{hPa}$ and

FIG. 2. (a) The power spectra of the intraseasonal GHT250 (MJJASO) over the UM core region (blue solid line); the red dashed line denotes the Markov red noise spectrum, and the blue/green dashed line represents a priori/a posteriori $99 \%$ confidence. The $x$ axis has been rescaled using the natural logarithm of frequency, and the corresponding $y$ axis is multiplied by frequency. (b) Fractional variance of 30-50d GHT250 against total GHT250 variance during MJJASO (shading; \%). The green line represents the UM, and the black rectangle is the UM core region. 
$30-50 d$ component $\&$ the raw data removing the climatological annual cycle
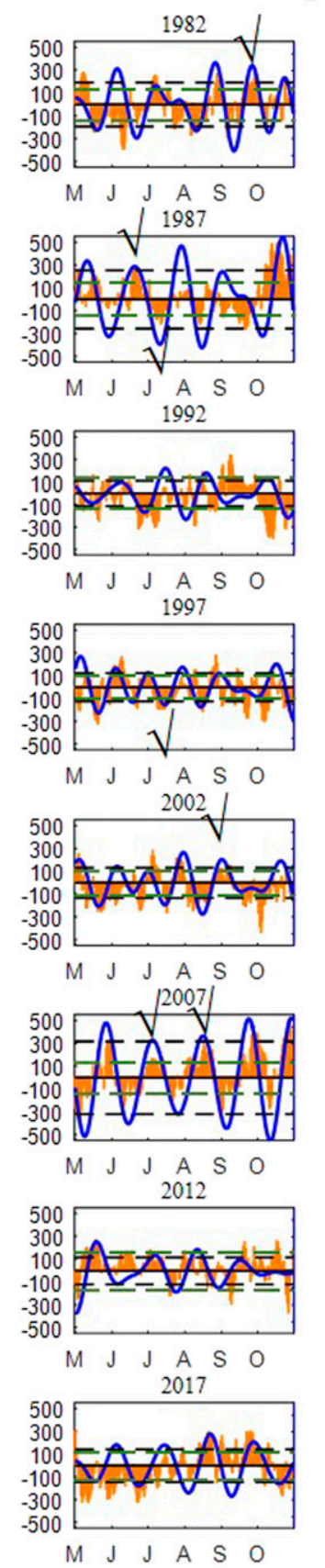

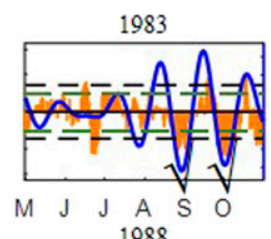

1988

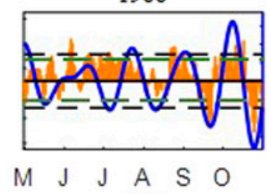

1993

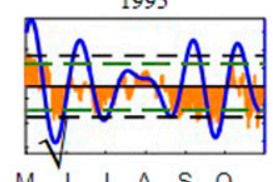

$M$ J J A O

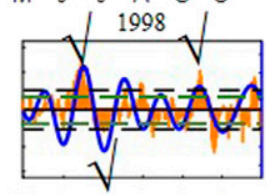

$M$ J J A S O

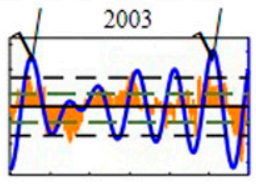

$\begin{array}{lllllll} & \mathrm{J} & \mathrm{J} & \mathrm{A} & \mathrm{S} & \mathrm{O}\end{array}$
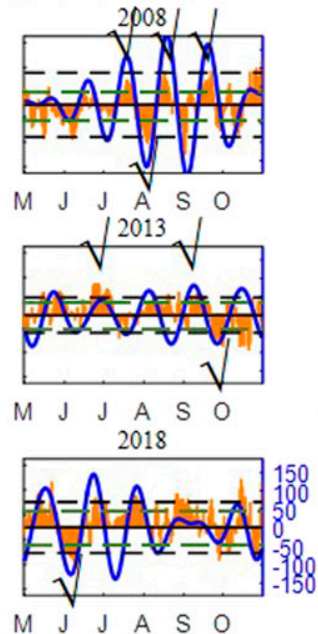
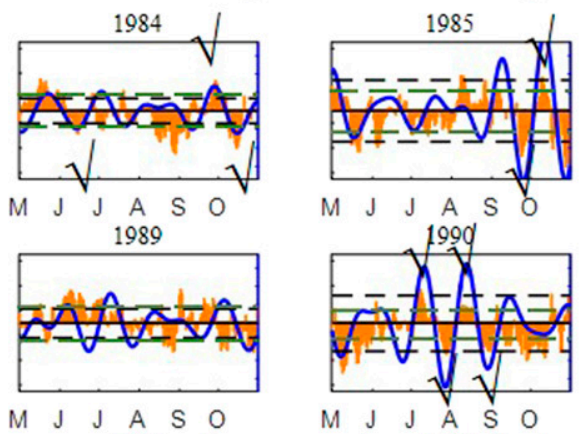

1994

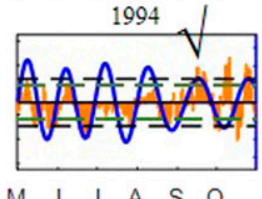

$M$ J J A S O
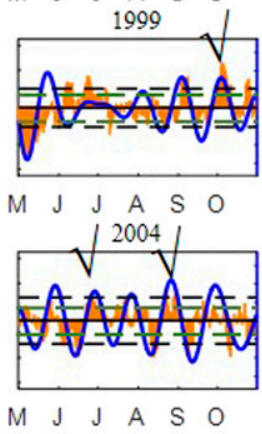

2009

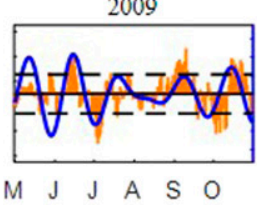

2014

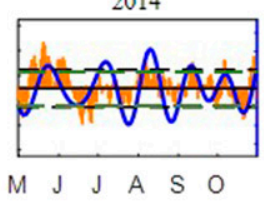

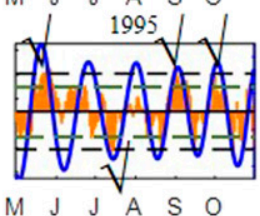

$M$ J J A S O

2005
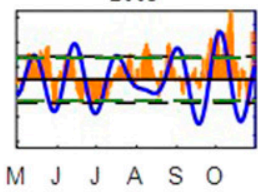

2010
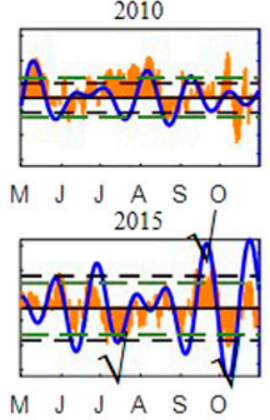

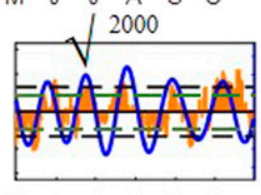

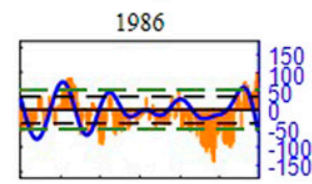

$M$ J J A S O

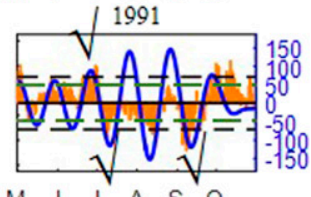

$M$ J J A S O

1996

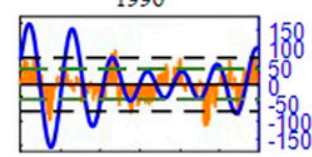

M J J A S O

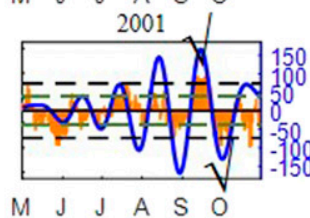

M J J A S O

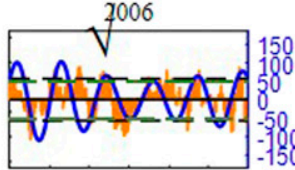

M J J A S O

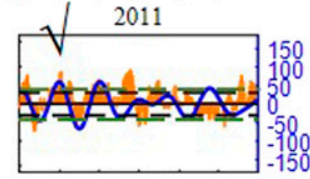

$M$ J J A S O

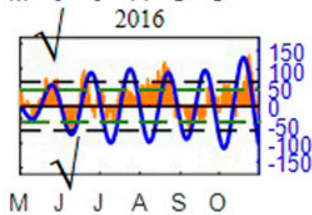

FIG. 3. Time series of raw data removing the climatological annual cycle (red bars; gpm) with values in the left $y$ axis and 30-50d filtered GHT250 (blue solid lines; gpm) with values in the right $y$ axis, averaged over the core region during each MJJASO of the 37 years. Dashed black (green) lines represent one standard deviation of 30-50d GHT250 (raw data removing the climatological annual cycle) of each individual boreal summer. A black check mark $(\checkmark)$ denotes the significant cases, selected according to the given criteria.

latitude $60^{\circ} \mathrm{N}$. Then, we calculate the variance of intraseasonal circulation at $250 \mathrm{hPa}$ over the Eurasian continent and find that two maximum centers locate over the domains of $55^{\circ}-68^{\circ} \mathrm{N}, 0^{\circ}-$ $24^{\circ} \mathrm{E}$ (eastern North Atlantic) and $58^{\circ}-65^{\circ} \mathrm{N}, 38^{\circ}-56^{\circ} \mathrm{E}$ (west of the Ural Mountains), respectively. While the dominant ISO periodicity over the eastern North Atlantic belongs to the high- frequency ISO (fewer than 30 days; not shown), which is beyond the scope of this study. Therefore, we determine the domain west of the Ural Mountains (UM; shown by the rectangle in Fig. 1b) to be the core region of this study. The other meteorological fields also demonstrate large intraseasonal variance over the UM domain (not shown). Additionally, the 
TABLE 1. The 53 significant LF-ISO events with dates of occurrence and event categories. The first four columns are the eastward propagating events, and the last four columns are the westward propagating events.

\begin{tabular}{|c|c|c|c|c|c|c|c|}
\hline $\begin{array}{l}\text { LF-ISO } \\
\text { event No. }\end{array}$ & Dates of occurrence & $\begin{array}{c}\text { Event } \\
\text { categories }\end{array}$ & Propagating & $\begin{array}{l}\text { LF-ISO } \\
\text { event No. }\end{array}$ & Dates of occurrence & $\begin{array}{c}\text { Event } \\
\text { categories }\end{array}$ & Propagating \\
\hline 1 & 11 Sep-10 Oct 1982 & + & Eastward & 27 & 22 May-3 July 1984 & - & Westward \\
\hline 2 & 13 Aug-15 Sep 1983 & - & Eastward & 28 & 11 Sep-15 Oct 1984 & + & Westward \\
\hline 3 & 15 Sep-19 Oct 1983 & - & Eastward & 29 & 28 Sep-2 Nov 1984 & - & Westward \\
\hline 4 & 9 Sep-10 Dec 1985 & - & Eastward & 30 & 12 Jun-11 Jul 1991 & + & Westward \\
\hline 5 & 25 Sep-28 Oct 1985 & + & Eastward & 31 & 26 Jun-26 Jul 1991 & - & Westward \\
\hline 6 & 29 May-11 Jul 1987 & + & Eastward & 32 & 27 Aug-28 Sep 1991 & - & Westward \\
\hline 7 & 21 Jun-29 Jul 1987 & - & Eastward & 33 & 3 May-7 Jun 1995 & + & Westward \\
\hline 8 & 24 Jun-27 Jul 1990 & + & Eastward & 34 & 8 Jun-9 Jul 2000 & + & Westward \\
\hline 9 & 7 Nov-13 Aug 1990 & - & Eastward & 35 & 30 Aug-2 Oct 2001 & + & Westward \\
\hline 10 & 27 Jul-29 Aug 1990 & + & Eastward & 36 & 15 Sep-21 Oct 2001 & - & Westward \\
\hline 11 & 12 Aug-15 Sep 1990 & - & Eastward & 37 & 15 Aug-16 Sep 2002 & + & Westward \\
\hline 12 & 5 May-11 Jun 1993 & - & Eastward & 38 & 1 May-1 Jun 2003 & + & Westward \\
\hline 13 & 28 Aug-6 Jun 1994 & + & Eastward & 39 & 19 Sep-20 Oct 2003 & + & Westward \\
\hline 14 & 26 Jun-1 Aug 1995 & - & Eastward & 40 & 13 Jun-12 Jul 2004 & + & Westward \\
\hline 15 & 18 Aug-18 Sep 1995 & + & Eastward & 41 & 11 Aug-12 Sep 2004 & + & Westward \\
\hline 16 & 18 Sep-19 Oct 1995 & + & Eastward & 42 & 27 Jun-2 Aug 2006 & + & Westward \\
\hline 17 & 1 Jul-30 Jul 1997 & - & Eastward & 43 & 14 Jun-27 Jul 2007 & + & Westward \\
\hline 18 & 1 Jun-3 Jul 1998 & + & Eastward & 44 & 27 Jul-5 Sep 2007 & + & Westward \\
\hline 19 & 17 Jun-19 Jul 1998 & - & Eastward & 45 & 16 May-16 Jun 2011 & + & Westward \\
\hline 20 & 30 Aug-3 Oct 1998 & + & Eastward & 46 & 10 Jun-18 Jul 2013 & + & Westward \\
\hline 21 & 19 Sep-19 Oct 1999 & + & Eastward & 47 & 8 Sep-16 Oct 2013 & - & Westward \\
\hline 22 & 4 Jun-3 Aug 2008 & + & Eastward & 48 & 29 Jun-30 Jul 2015 & - & Westward \\
\hline 23 & 19 Jun-19 Aug 2008 & - & Eastward & 49 & 5 Sep-8 Oct 2015 & + & Westward \\
\hline 24 & 8 Mar-4 Sep 2008 & + & Eastward & 50 & 21 Sep-25 Oct 2015 & - & Westward \\
\hline 25 & 4 Sep-6 Oct 2008 & + & Eastward & 51 & 10 May 2016-9 Jun 2016 & + & Westward \\
\hline \multirow[t]{2}{*}{26} & 22 Aug-27 Sep 2013 & + & Eastward & 52 & 25 May-24 Jun 2016 & - & Westward \\
\hline & & & & 53 & 17 May-23 Jun 2018 & - & Westward \\
\hline
\end{tabular}

UM domain corresponds to a climatological ridge, where blocking highs often occur during summer (Liu et al. 2018).

To investigate the dominant intraseasonal periodicity of the UM core region, we apply a power spectral analysis for the intraseasonal component of 250-hPa GHT (GHT250) over the core region, as shown in Fig. 2a. A significant spectrum peak is found in the band between 30 and 50 days, with a maximum of 36.7 days. Note that there are two other peaks, at 10-20 days and 21-29 days, which have been reported in other studies (Yang et al. 2010). In this study, since we focus on the LF-ISO (with more than 30-day periodicity), the 30-50day (hereafter 30-50d) band of intraseasonal component is selected as the target of this study. We also apply wavelet analysis and multiyear averaged spectrum to validate the robustness of this selected spectrum, and the results are almost similar. Meanwhile, we calculate the fractional variance of the 30-50d component against total variance over the Eurasian continent during boreal summer, and find that the UM domain is also the maximum center of the 30-50d component, accounting for about $34 \%$ of total variance (Fig. 2 b).

\section{Two types of mid-high-latitude LF-ISOs}

To characterize the structures and propagation of the LF-ISO over the UM core region, we first choose the significant LF-ISO events during the past 37 summers (1982-2018). The areaaveraged daily time series of both raw GHT250 removing the climatological annual cycle and 30-50d filtered GHT250 over the UM domain are presented year by year in Fig. 3. Here, the peak of the time series denotes an anticyclonic anomaly (increased ridge/decreased trough), and the valley represents a cyclonic anomaly (decreased ridge/increased trough). A positive (+) LF-ISO event represents an intraseasonal cycle of an anomalous ridge establishment while a negative $(-)$ LF-ISO event means an intraseasonal development of a trough anomaly. The criteria for selecting the significant LF-ISO events are that 1) the peak and the valley phases exceed one standard deviation of the boreal summer area-averaged 30-50d GHT250, which ensures the event is a significant 30-50d event; 2) the raw data removing the climatological cycle around the peak (valley) must exceed one standard deviation for 4 consecutive days, which ensures the event is also significant in unfiltered data; and 3) the persistent days with positive (negative) values around the peak (valley) should be within 15-25 days, which ensures the duration of the event is $30-50$ days. When one peak phase and two valley phases of one LF-ISO cycle reach the above thresholds, this event is chosen as a positive $(+)$ event. When one valley and two peaks of one event meet the requirements, a negative $(-)$ event is picked out. Consequently, 53 significant LF-ISO events are selected from 37 summers. Through making a case-by-case 


\section{GHT250}
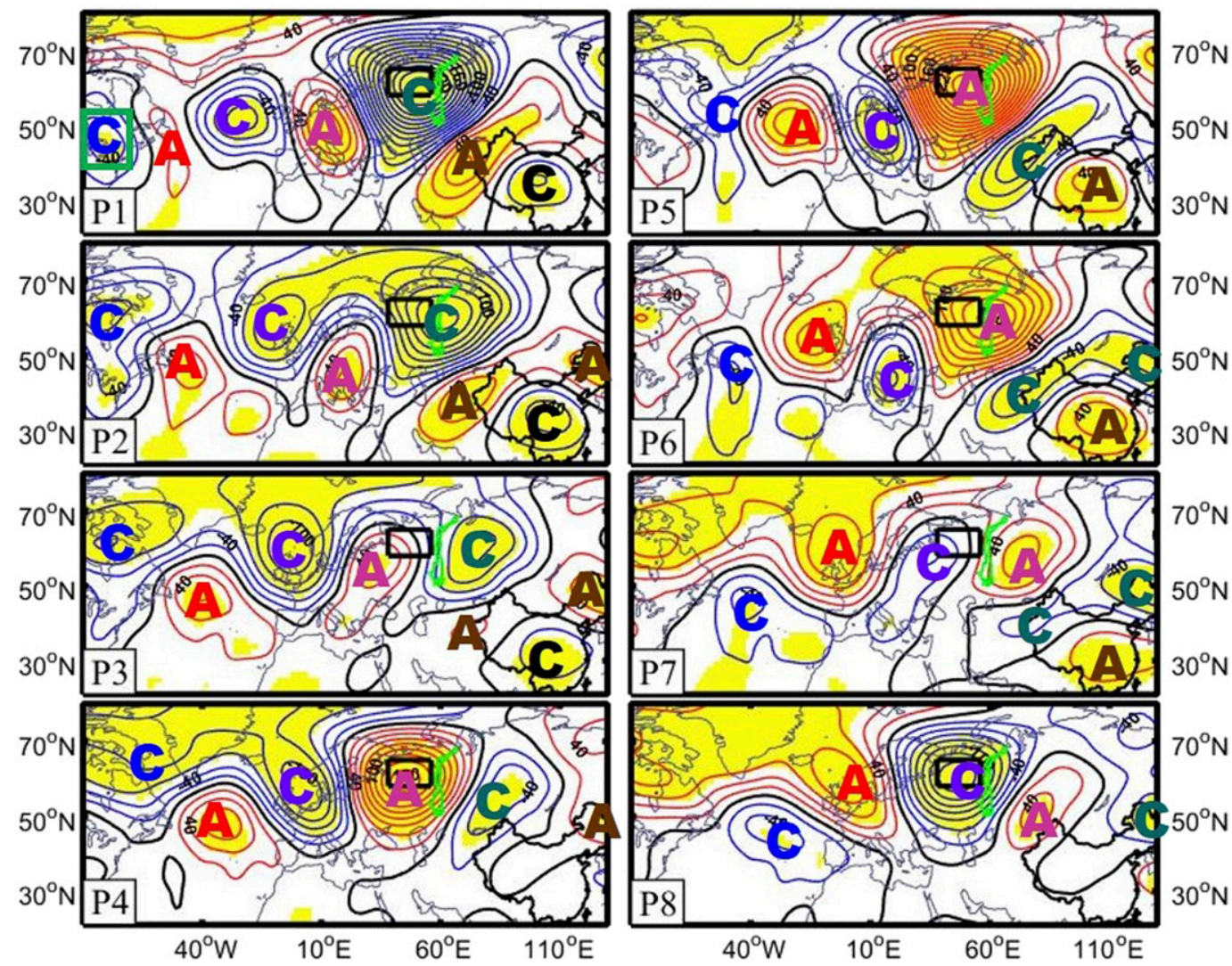

FIG. 4. Temporal evolution of 30-50d GHT250 (contour; gpm; interval: 20 gpm) based on phase composite analysis for the eastward propagating events. The black contour is $0 \mathrm{gpm}$, and red (blue) contours present the positive (negative) values. Shading shows the results above the $95 \%$ confidence level. The green line represents the UM, and the black rectangle is the UM core region. The green rectangle is the source region of eastward propagating wave, only shown in phase 1 . The letter "A" denotes the center of the anticyclonic anomaly, and "C" denotes the cyclonic anomaly.

analysis of these 53 LF-ISO events (Wang and Rui 1990; Gao et al. 2017), we find that they can be divided into two categories according to their propagating direction (i.e., eastward propagating events and westward propagating events). Table 1 lists all of the LF-ISO events, including the dates of occurrence, event categories $(+$ or - ), and propagating types (eastward or westward). There are 26 eastward propagating events and 27 westward propagating events. Among these, 15 positive events and 11 negative events belong to eastward propagating events, and 17 positive events and 10 negative events feature westward propagation.

a. Spatiotemporal evolutions of the two types of mid-high-latitude LF-ISOs

We additionally investigate the spatial structures and temporal evolutions associated with these two types of LF-ISOs over the UM domain. We make a composite analysis of positive and negative events separately for both the eastward propagating and the westward propagating events. The results show that the features in positive events roughly exhibit a mirror image of those in the negative events. Therefore, to better distinguish the results, we make the composite of positive events and the mirror of negative events in the following analysis.

\section{1) EASTWARD PROPAGATING LF-ISO}

To describe the horizontal propagating characteristics of eastward propagating LF-ISO, we make the composite of 3050d GHT250 for 15 positive events and the mirror image of 11 negative events, as shown in Fig. 4. The most significant feature related to the LF-ISO of GHT250 over the UM domain is a nonstationary wave train spanning the entire northern Atlantic/ Eurasian continent in the mid-high latitudes, notably along the latitudes between $40^{\circ}$ and $60^{\circ} \mathrm{N}$. The LF-ISO wave train initiates over eastern North America (the green rectangle in Fig. 4), moves eastward across northeastern North America/western North Atlantic, central North Atlantic, and western Europe, and then enhances its amplitude over the UM and subsequently migrates eastward across the UM. Afterward, the LF-ISO wave train moves southeastward to northwestern China and eventually reaches eastern China. 
(a) GHT500
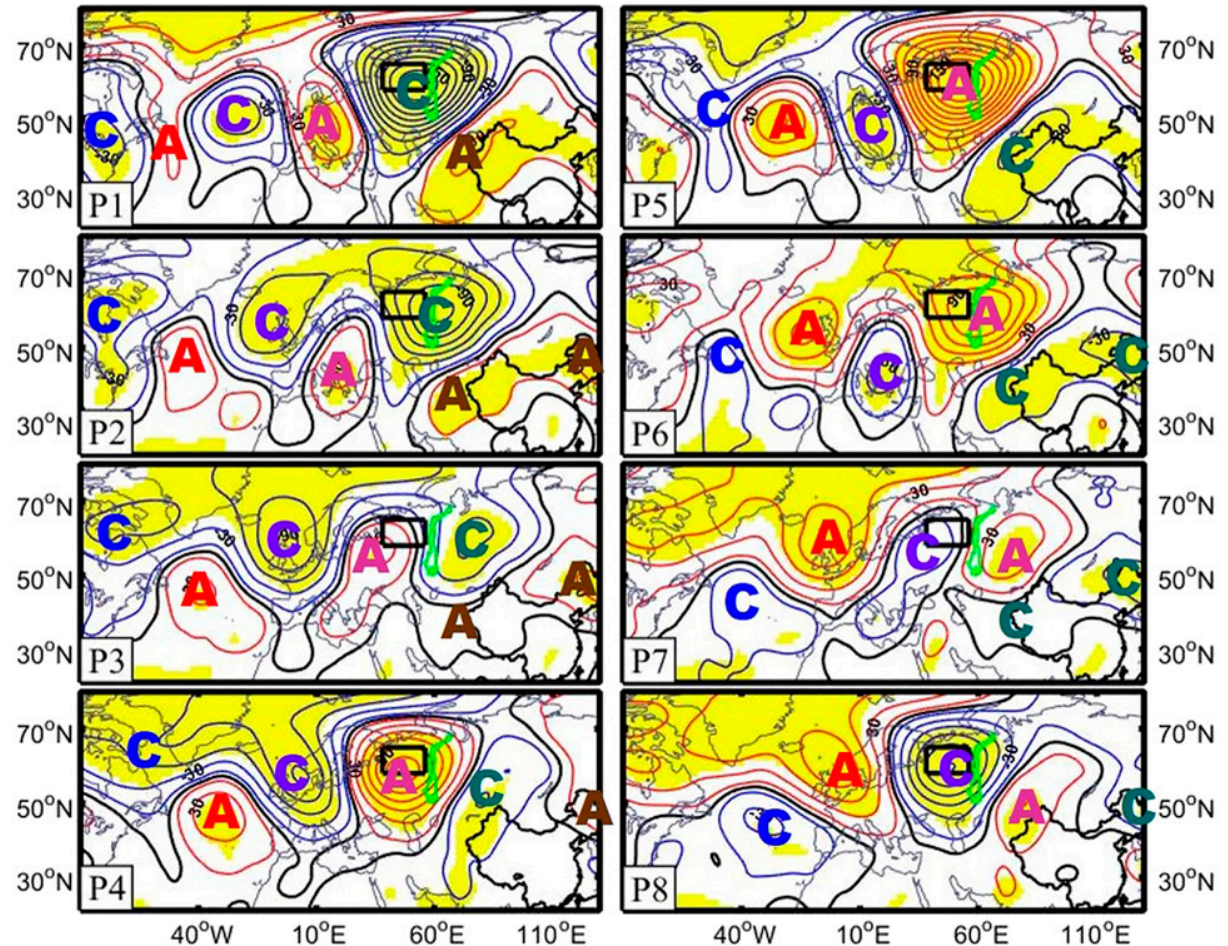

(b) GHT850
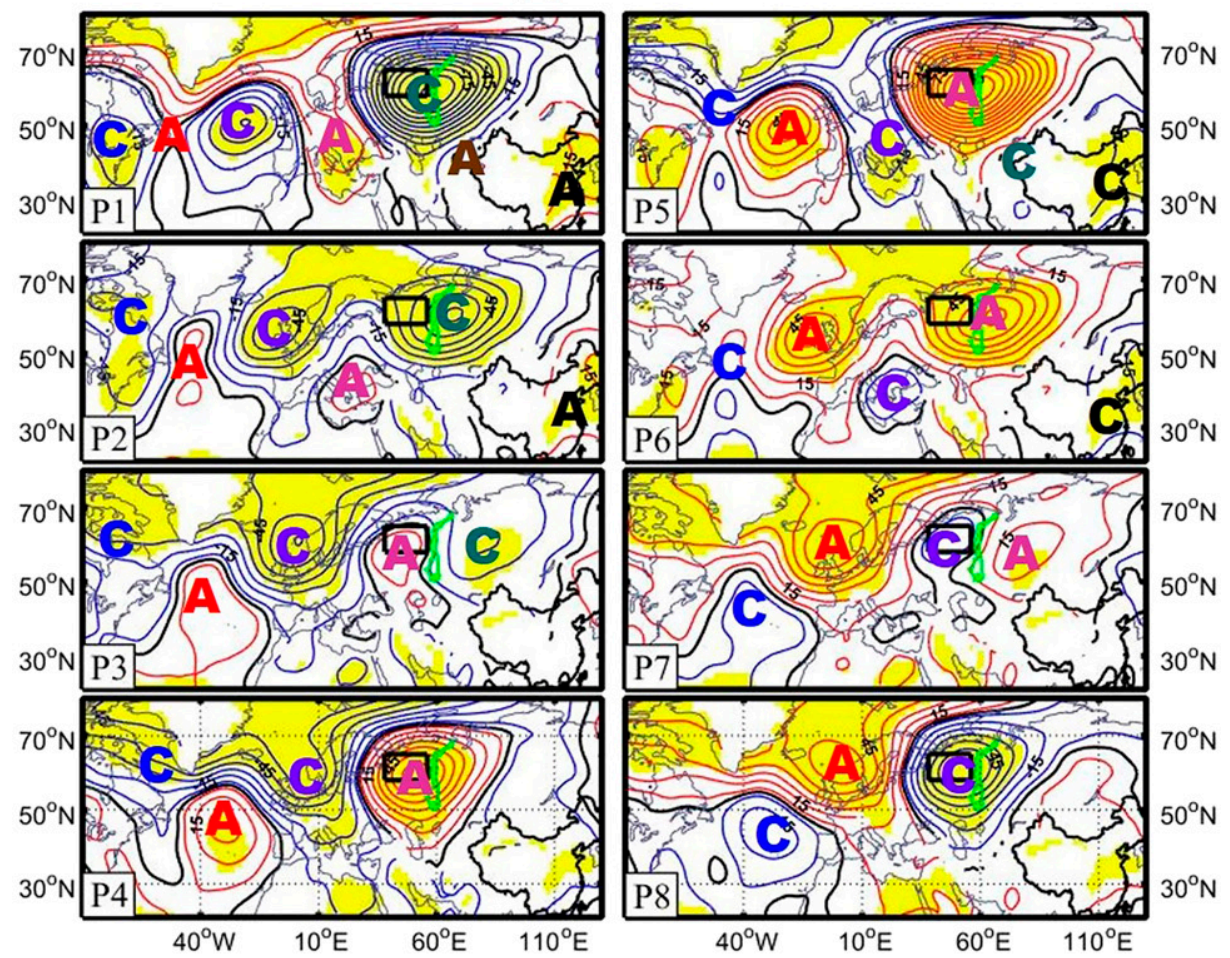

FIG. 5. As in Fig. 4, but for (a) GHT500 (contour; gpm; interval: 15 gpm) and (b) GHT850 (contour; gpm; interval: $10 \mathrm{gpm}$ ). 


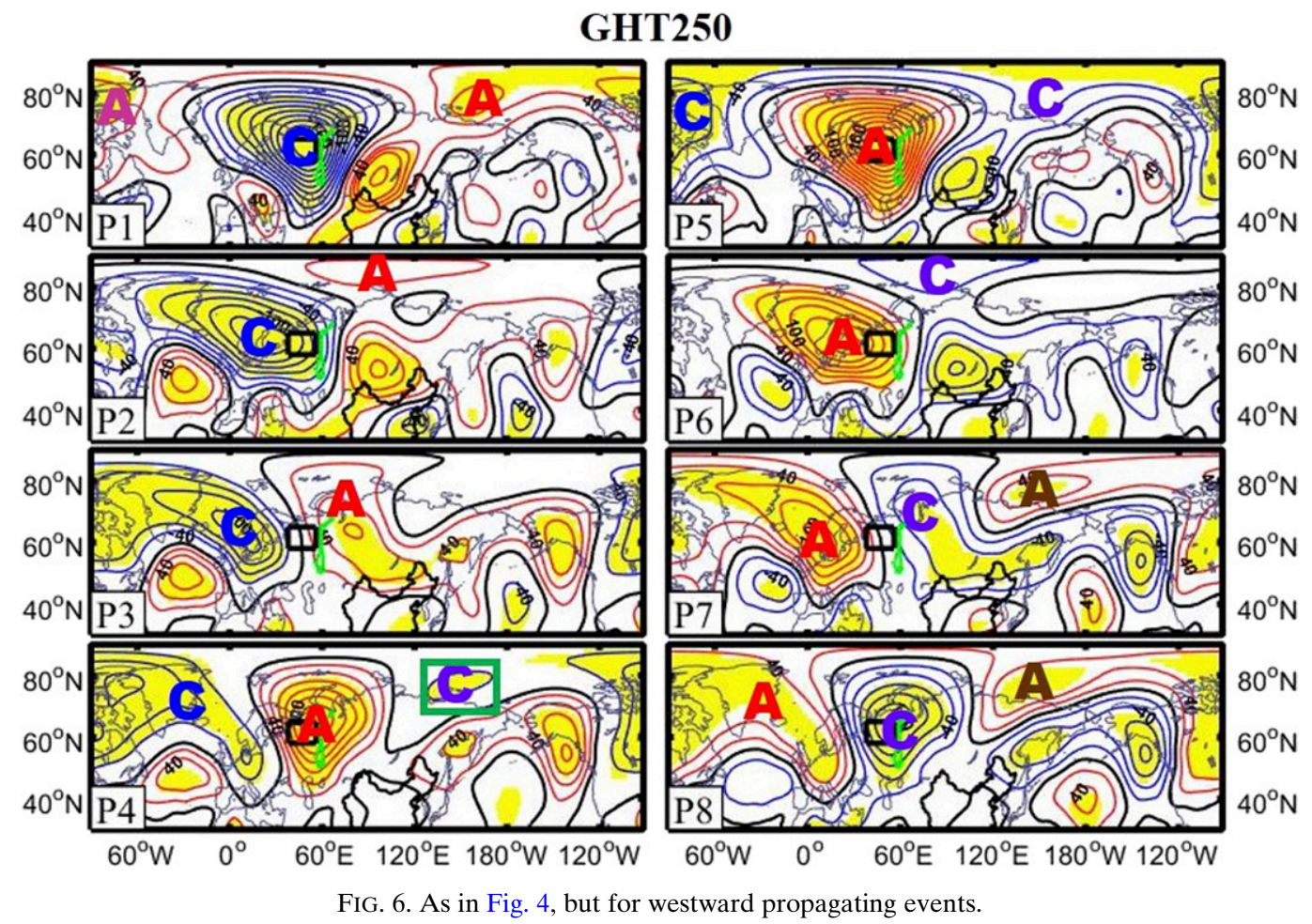

We also examine the features of horizontal propagation in both the middle and lower tropospheric atmosphere. The above-mentioned eastward propagation can be clearly seen in the middle-to-lower troposphere (Fig. 5). The LF-ISO wave train exhibits an evident barotropic structure throughout the entire troposphere in the mid-high latitudes north of $40^{\circ} \mathrm{N}$ (Figs. 4 and 5). In the latitudes south of $40^{\circ} \mathrm{N}$, however, the barotropic structure changes to baroclinic structure, particularly over eastern China-for example, at phase 6 an anomalous high in the upper troposphere $(250 \mathrm{hPa})$ and an anomalous low in the lower troposphere $(850 \mathrm{hPa})$ simultaneously occur over eastern China (Figs. 4 and 5). To quantitatively measure the speed of the eastward propagating LF-ISO, we calculate the propagating vector based on a local lead-lag correlation method (Lau and Lau 1990). According to the path of the eastward propagating LF-ISO wave train, we take the area of $28^{\circ}-65^{\circ} \mathrm{N}, 90^{\circ} \mathrm{W}-130^{\circ} \mathrm{E}$ as the key eastward propagating region. As a result, the area-averaged speed in this region is $1.04 \mathrm{~m} \mathrm{~s}^{-1}$. The propagating direction is primarily northeastward to the west of the UM, with a propagating speed of $1.01 \mathrm{~m} \mathrm{~s}^{-1}$, changing to southeastward to the east of the UM, with a speed of $1.13 \mathrm{~m} \mathrm{~s}^{-1}$.

\section{2) WESTWARD PROPAGATING LF-ISO}

Comparably, we make a composite analysis for the 17 positive westward propagating events and the mirror image of the 10 negative events in the upper, middle, and lower troposphere, respectively, as shown in Figs. 6 and 7. There is a nonstationary westward propagating wave train linked with the
LF-ISO over the UM domain in the mid-high latitudes, mainly along the higher latitudes between $60^{\circ}$ and $80^{\circ} \mathrm{N}$, and its pathway is quasi-circumpolar. This LF-ISO wave train is similar to the findings of Branstator (1987) and Ghil and Mo (1991) for winter. The LF-ISO wave train initiates over the East Siberian Sea (the green rectangle in Fig. 6), moves southwestward, and enhances its amplitude near the UM. After migrating westward across the UM, the LF-ISO wave train weakens and moves continually westward to Greenland, eventually reaches the Canadian Arctic Archipelago. The westward propagating LF-ISO wave train also exhibits an evident barotropic structure throughout the entire troposphere (Figs. 6 and 7). As before, we calculate the propagating vector and take the area of $60^{\circ}-80^{\circ} \mathrm{N}$, $100^{\circ} \mathrm{W}-180^{\circ}$ as the key westward propagating region, according to the path of the westward propagating LF-ISO wave train. As a result, the area-averaged speed in this region is $-1.53 \mathrm{~m} \mathrm{~s}^{-1}$.

\section{b. Decadal preferences of the two types of mid-high-latitude LF-ISOS}

The observational analysis above shows that there are two dominant types of atmospheric LF-ISOs with different propagating properties over the mid-high-latitude Eurasian continent during boreal summer from 1982 to 2018. Both of their signals are significant and enhanced over the UM domain. To investigate whether the two types of LF-ISOs favor different temporal epochs, we count the dates of their occurrence case by case, along with seasons and years, as shown in Fig. 8a. The most evident feature is that the eastward propagating LF-ISO events occur mainly during the period before 2000, while the 
(a) GHT500
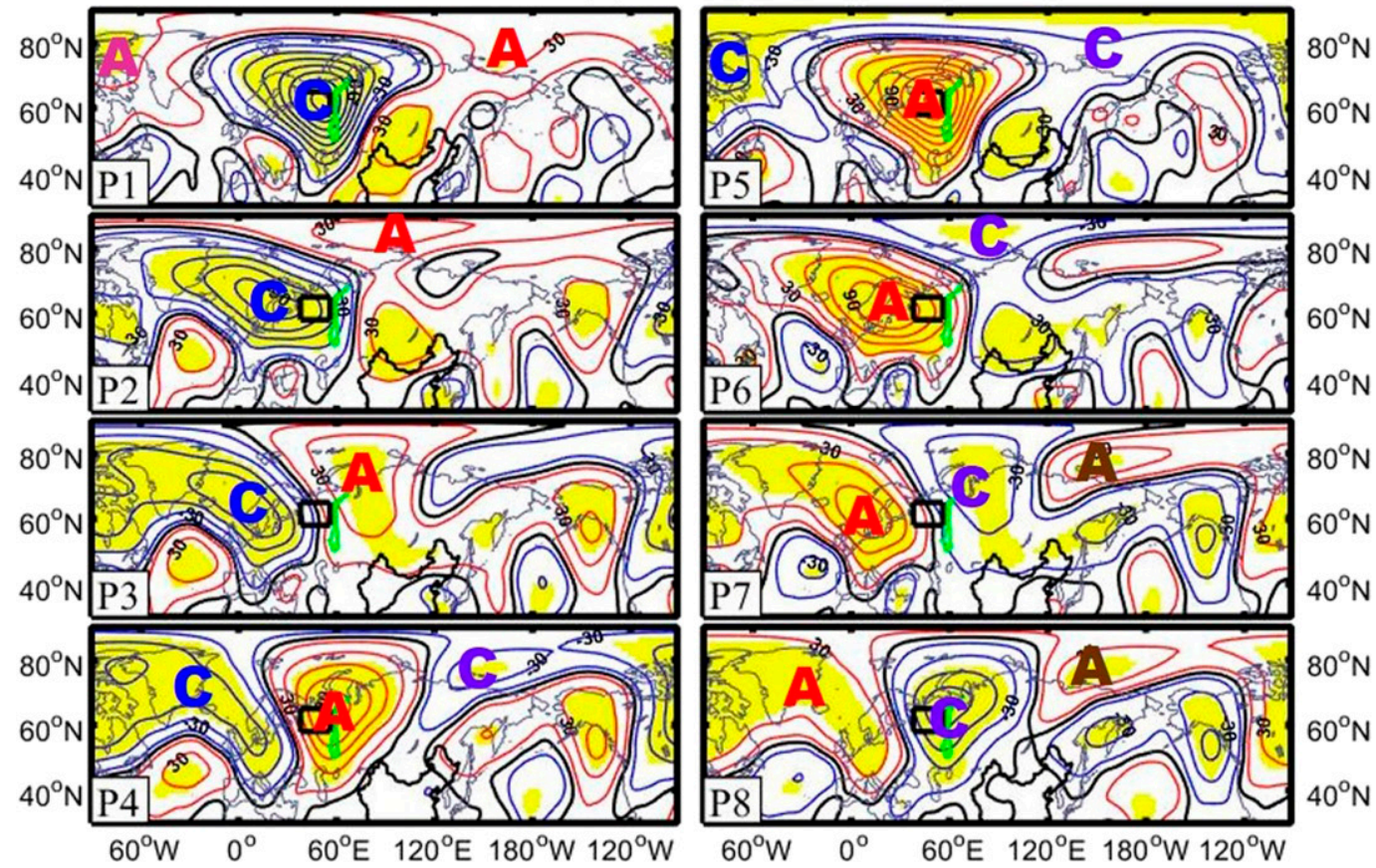

(b) GHT850
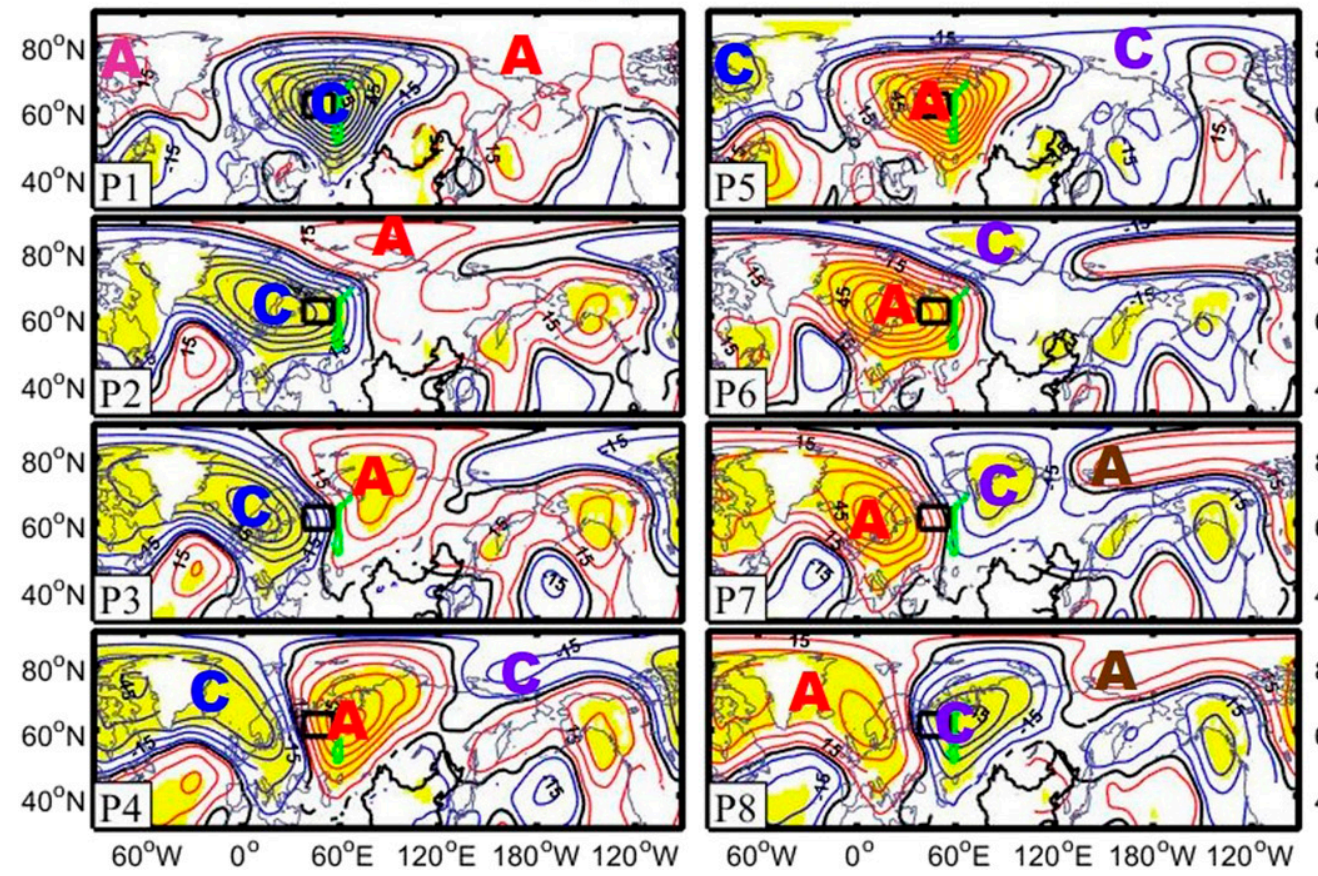

$80^{\circ} \mathrm{N}$ $60^{\circ} \mathrm{N}$ $40^{\circ} \mathrm{N}$ $80^{\circ} \mathrm{N}$ $60^{\circ} \mathrm{N}$ $40^{\circ} \mathrm{N}$ $80^{\circ} \mathrm{N}$ $60^{\circ} \mathrm{N}$ $40^{\circ} \mathrm{N}$ $80^{\circ} \mathrm{N}$ $60^{\circ} \mathrm{N}$ $40^{\circ} \mathrm{N}$

FIG. 7. As in Fig. 5, but for westward propagating events.

westward propagating LF-ISO events significantly increase after 2000. Thus, we divide the 37-yr study period (1982-2018) into two comparable epochs: 1982-99 (hereafter pre-2000) and 2001-18 (hereafter post-2000). The results show that the eastward propagating events occurring in the pre-2000 epoch account for $81 \%$ of their total events, while the westward propagating events occurring in the post-2000 epoch account for $74 \%$ of their total, as shown in Fig. 8 b. 
(a)

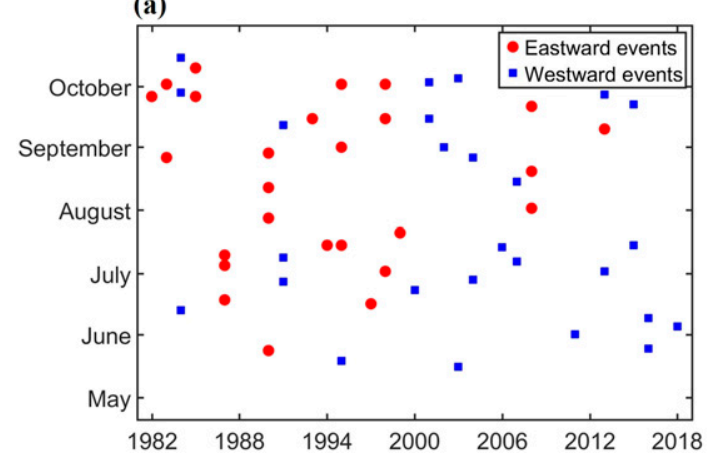

(b)

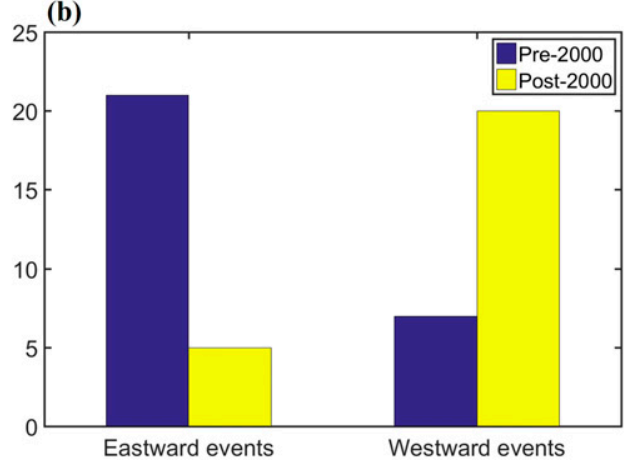

FIG. 8. (a) Year-by-year distribution of the two types of LF-ISO events. (b) Decadal total numbers of the eastward/ westward propagating events.

\section{c. Tropical footprints of the two types of mid-high-latitude LF-ISOs}

We further examine the simultaneous intraseasonal evolutions in tropical convection and circulation accompanied with the above-mentioned eastward and westward propagating LFISO wave trains. Here, composite analysis similar to that in section $4 \mathrm{a}$ is applied. The 250 -hPa potential function $(\chi 250)$, which represents the upper-level convergence/divergence, and OLR are both used to depict the corresponding tropical atmospheric intraseasonal evolutions. Because the upper-level anomalous divergence (convergence) is in good agreement with the enhanced (suppressed) convection anomaly, only the upper-level potential function fields are shown (Fig. 9). The most significant feature related to the eastward propagating LF-ISO is a zonal dipole of $\chi 250$ anomalies, which is out of phase over the northern Indian Ocean and tropical western Pacific. At phase 1, an upper-level divergence center with enhanced convection spans the Arabian Peninsula. It then moves slightly eastward over the Arabian Sea and further enhances at phases 2-3, before delaying over the Indian Peninsula at phases 4-5. Simultaneously at phase 1 , an evident upper-level convergence maximum center accompanied with a suppressed convection appears over the tropical western Pacific, roughly along $5^{\circ} \mathrm{S}$. Afterward, the convergence maximum center extends slightly northward to the Philippine Sea, enhances at phase 2, and disappears at phase 4 . A mirror image of the sequence occurs in the second half-cycle from phase 5 to phase 8 .

In contrast, the most striking characteristic related to the westward propagating LF-ISO in the tropics is a zonal in-phase dipole of $\chi 250$ anomalies over the northwestern Indian Ocean and tropical western Pacific, as shown in Fig. 10. At phase 2, two anomalous centers of upper-level divergence/enhanced convection simultaneously locate over the western tropical Indian Ocean and Maritime Continent. These anomalies are quasi-in-phase and quasistationary, although the Maritime Continent anomaly moves slightly northeastward. The upper-level divergence anomaly with enhanced convection over the western tropical Indian Ocean becomes significant at phases $2-3$ and decays at phases $4-5$, while the Maritime Continent convection delays by one phase and is at its strongest at phases 3-4. Further analysis shows that the tropical anomalies demonstrate a baroclinic structure in both eastward and westward propagating modes (not shown).

\section{Discussion}

\section{a. Origins of the two types of mid-high-latitude LF-ISOs}

The results presented in section $4 \mathrm{a}$ exhibit that the eastern North America (the green rectangle in Fig. 4) is the original region of the eastward propagating LF-ISO wave (hereafter E-Source) while the East Siberian Sea (the green rectangle in Fig. 6) is the source region of westward propagating LF-ISO (hereafter W-Source). And we attempt to understand the origin of these two types of LF-ISOs over their source regions. First, we calculate the Rossby wave source (RWS), which has been widely used in the study of ISO (Seo and Lee 2017; Tseng et al. 2019; Cui et al. 2020). Figure 11a shows the horizontal distributions of RWS over the E-Source during the cyclonic genesis period. Here the cyclonic genesis period is purposely defined as the period from -5 day to phase 1 in each eastward propagating event. The composite results show that there is a maximum positive RWS over the E-Source region, which locates in the inlet region of the Atlantic jet stream. Previous studies have demonstrated that the inlet/exit region of the jet stream is characterized by the large zonal and meridional wind gradients, which provides favorable conditions for a strong Rossby wave source (Simmons et al. 1983; Chen et al. 2020). Second, we calculate the WAF, which was originally formulated by Takaya and Nakamura (2001) and purposely developed by Yang and $\mathrm{Li}$ (2016) for the intraseasonal wave train. Figure 11b shows the horizontal distributions of the WAF and its divergence fields at $250 \mathrm{hPa}$ in the same cyclonic genesis period. It can be clearly seen that there is a large WAF convergence over the E-Source region, showing that E-Source region is the energy source of the eastward propagating LFISO wave train.

Comparably, we also examine the horizontal distributions of the WAF and its divergence fields, as well as the RWS, at $250 \mathrm{hPa}$ over the W-Source during the cyclonic genesis period. Here the cyclonic genesis period for the westward propagating 


\section{$X 250 \&$ GHT250}
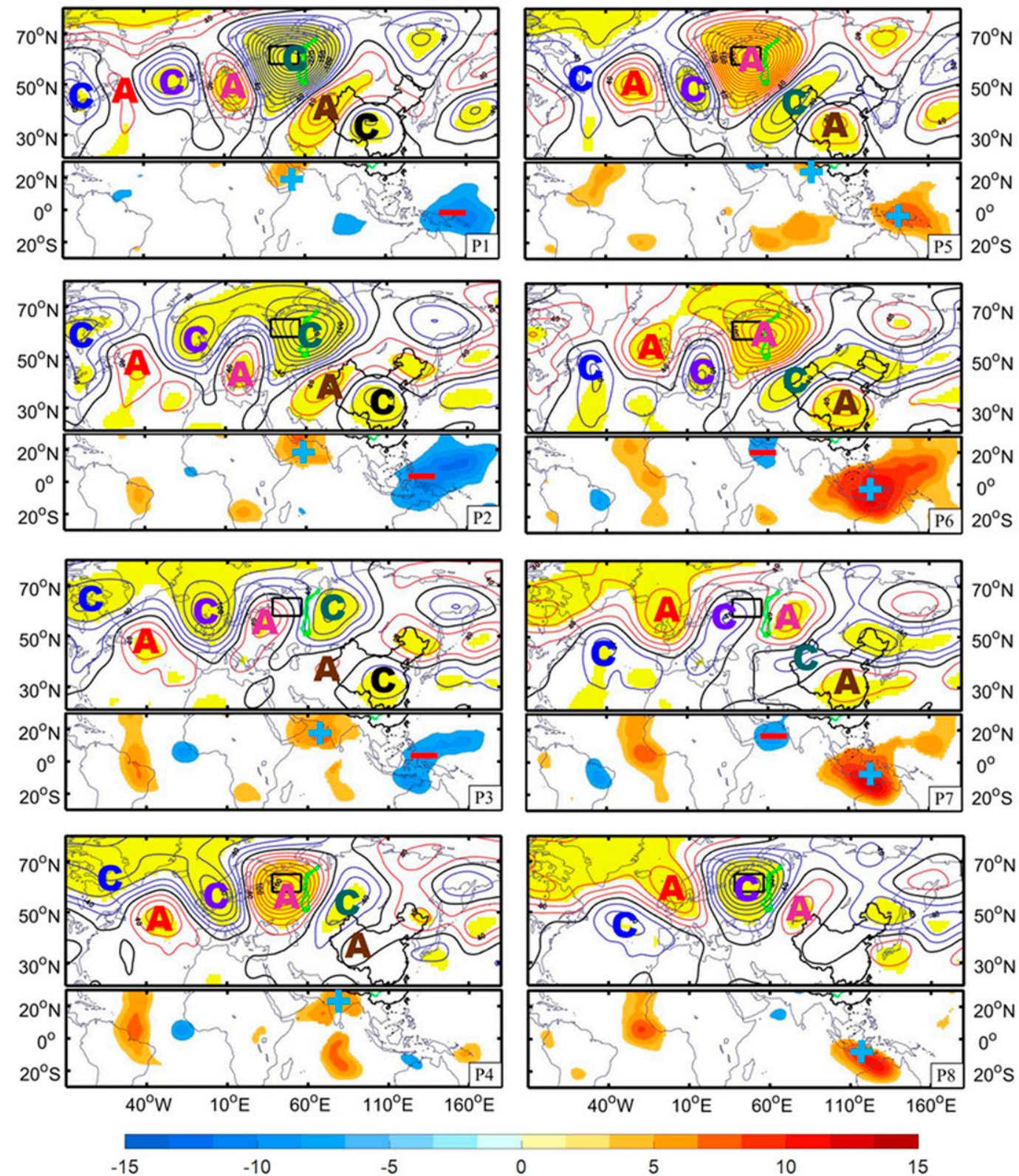

FIG. 9. Phase composite of the temporal evolutions of $30-50 \mathrm{~d}$ potential function at $250 \mathrm{hPa}$ ( $\chi 250$; shading; $\left.10^{-6} \mathrm{~s}^{-1}\right)$ in the tropics along with mid-high-latitude eastward propagating LF-ISO events measured by $30-50 \mathrm{~d}$ GHT250. Only the results of the $\chi 250$ above the $95 \%$ confidence level are shown. A plus sign ( + ) represents the upper-level divergence center with enhanced convection, and a minus sign $(-)$ indicates the upper-level convergence center with suppressed convection. The green line represents the UM, and the black rectangle is the UM core region. The letter "A" denotes the center of the anticyclonic anomaly, and "C" denotes the cyclonic anomaly.

mode refers to the period from -5 day to phase 4 in each westward propagating event. As a result, Figs. 11c and $11 \mathrm{~d}$ show that there are the large WAF convergence and RWS over $\mathrm{W}$-Source region, which implies W-Source region is the energy source of the westward propagating LF-ISO wave train. b. Causes for the different decadal preferences of the two types of mid-high-latitude LF-ISOS

Section $4 \mathrm{~b}$ has shown that the eastward and westward propagating mid-high-latitude LF-ISOs have different decadal 
$X 250$ \& GHT250
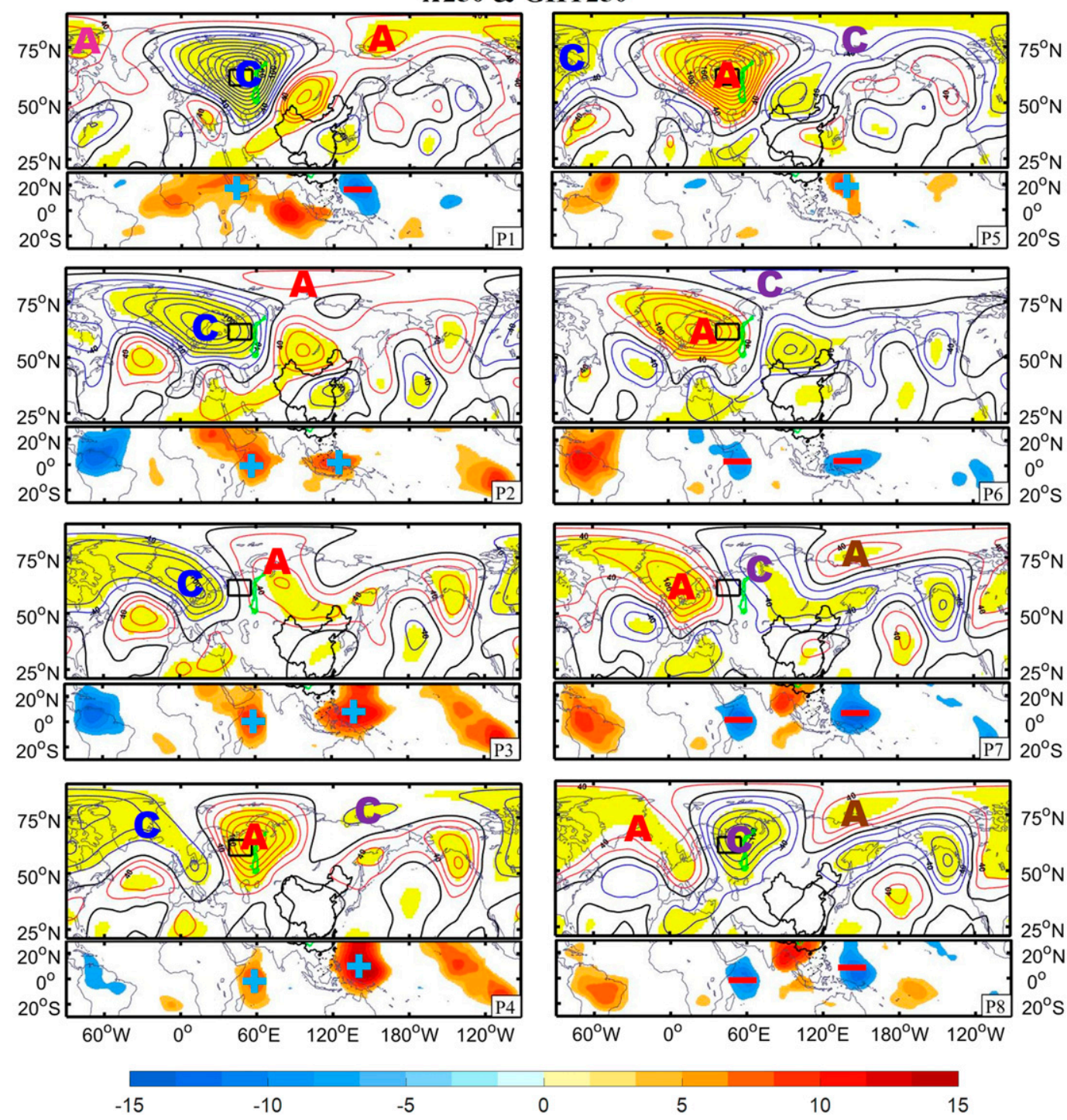

FIG. 10. As in Fig. 9, but for westward propagating events.

preferences. That is, the eastward propagating events favor the pre-2000 epoch while the westward propagating events preferentially appear in the post-2000 epoch. Why do they have different epochal preferences?

These two propagating modes have different transient wave source regions. Therefore, we purposely examine the epochal differences of the E-Source and W-Source. Previous studies have suggested that the origin of mid-high-latitude wave trains is triggered by efficient kinetic energy extraction from the basic state (e.g., Simmons et al. 1983; Ding and Wang 2007). We calculate the area-averaged barotropic kinetic energy conversion $(\overline{\overline{\text { CKiso }}})$ over the E-Source and W-Source, respectively, during boreal summer in the two epochs (Fig. 12). Here, the positive value of $\overline{\overline{\mathrm{CKiso}}}$ represents energy conversion from the mean flow to the intraseasonal perturbation, and the negative value represents energy conversion from the intraseasonal perturbation to the mean flow (Hoskins et al. 1983; Wang et al. 2013). The results show that the $\overline{\text { CKiso }}$ over the E-Source is $6.93 \times 10^{-5} \mathrm{~m}^{2} \mathrm{~s}^{-3}$ in the pre-2000 epoch whereas in the post-2000 epoch it decreases significantly to $1.74 \times 10^{-5} \mathrm{~m}^{2} \mathrm{~s}^{-3}$ (all above the $95 \%$ confidence level against the climatology). In contrast, for westward propagating LF-ISO wave train, the area-averaged $\overline{\overline{\mathrm{CKiso}}}$ over the W-Source is $-5.58 \times$ $10^{-5} \mathrm{~m}^{2} \mathrm{~s}^{-3}$ in the pre-2000 epoch and in the post-2000 epoch it increases significantly to $3.32 \times 10^{-5} \mathrm{~m}^{2} \mathrm{~s}^{-3}$ (all above the $95 \%$ confidence level against the climatology). The results suggest that the intraseasonal perturbation over their source regions more easily obtains energy from mean flow in the pre-2000 (post-2000) over the E-Source (W-Source).

Furthermore, numerous studies have reported that the North Atlantic Oscillation (NAO) experiences a pronounced 
(a) RWS for eastward propagating LF-ISO

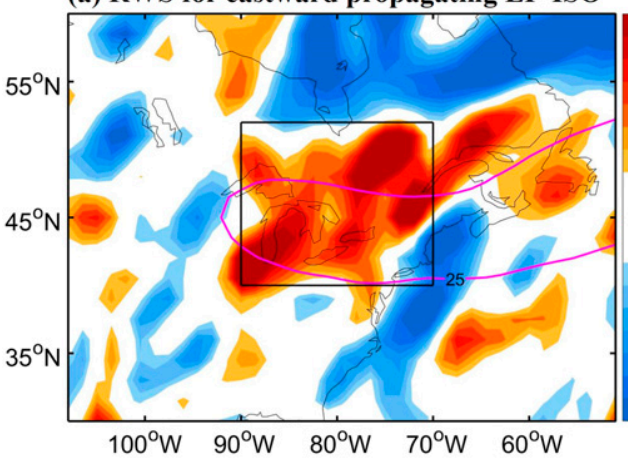

(c) RWS for westward propagating LF-ISO

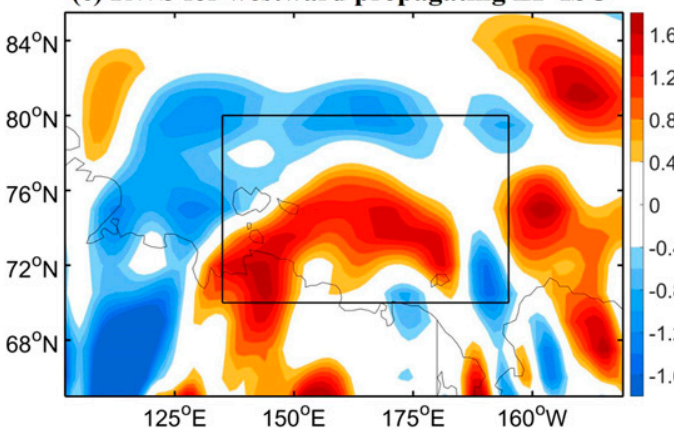

(b) WAF for eastward propagating LF-ISO

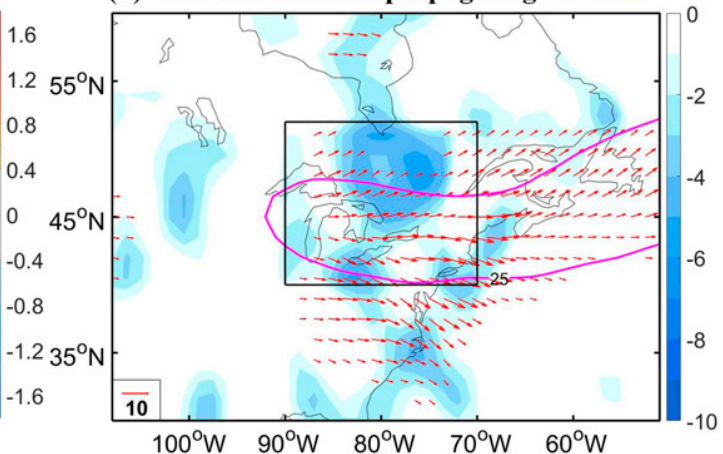

(d) WAF for westward propagating LF-ISO

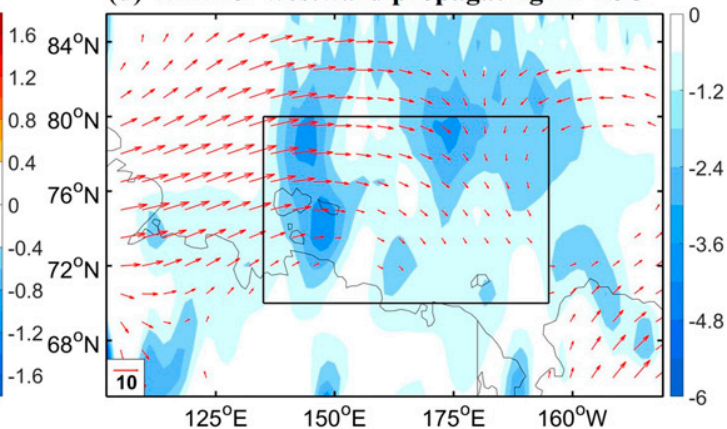

FIG. 11. Horizontal distribution of (a) Rossby wave source (RWS; shading; $10^{-10} \mathrm{~s}^{-2}$ ) and (b) wave activity flux (WAF; vector; $\mathrm{m}^{2} \mathrm{~s}^{-2}$ ) and its divergence (shading; $10^{-5} \mathrm{~m} \mathrm{~s}^{-2}$ ) at $250 \mathrm{hPa}$ during the cyclonic genesis period for the eastward propagating events. The pink line is zonal wind contour of $25 \mathrm{~m} \mathrm{~s}^{-1}$ that denotes the location of the subtropical westerly jet. The black rectangle is the genesis region of the eastward propagating LF-ISO (E-Source). Only the results above the $95 \%$ confidence level are shown. (c),(d) As in (a) and (b), but during the cyclonic genesis period for the westward propagating events. The black rectangle is the genesis region of the westward propagating LF-ISO (W-Source).

decadal change, which shifted from a positive phase $\left(\mathrm{NAO}^{+}\right)$ to a negative phase $\left(\mathrm{NAO}^{-}\right)$after 2000 (e.g., Li et al. 2013; Delworth et al. 2016; Zhao et al. 2020). Additionally, the $\mathrm{NAO}^{+}$enhances the upper-level westerly winds along the

\section{Barotropic energy conversion}

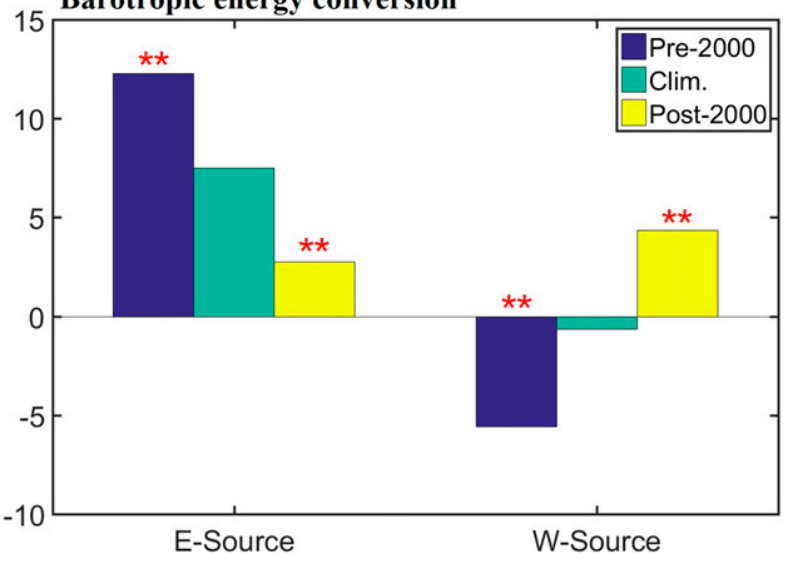

FIG. 12. Area-averaged barotropic kinetic energy conversion $\left(\overline{\overline{\mathrm{CKiso}}} ; 10^{-5} \mathrm{~m}^{2} \mathrm{~s}^{-3}\right)$ over the E-Source and W-Source. Two asterisks $(* *)$ indicate results above the $95 \%$ confidence level. latitudes between $50^{\circ}$ and $65^{\circ} \mathrm{N}$, as shown in Fig. $13 \mathrm{a}$, which is also addressed in Delworth et al. (2016). The stronger upperlevel westerly winds are along the eastward propagating path over the North Atlantic, thus facilitating the eastward propagation of LF-ISO (Fig. 13a). Similarly, according to previous research (e.g., Qian et al. 2020), the Arctic Oscillation (AO) also shows a significant decadal change from positive $\left(\mathrm{AO}^{+}\right)$to negative $\left(\mathrm{AO}^{-}\right)$ phase after 2000 . The $\mathrm{AO}^{-}$increases the high-latitude easterly winds between $60^{\circ}$ and $80^{\circ} \mathrm{N}$, which can favor the westward propagation of LF-ISO along its propagating path (Fig. 13b).

\section{c. Understanding the coherent tropical atmospheric intraseasonal variations}

Numerous studies have addressed the close links between the tropical and extratropical regions in theoretical (e.g., Hoskins and Yang 2000; Hall et al. 2017), observational (Zangvil and Yanai 1980; Yang and Wu 2019), and modeling terms (e.g., Lin et al. 2000, 2007; Ray and Zhang 2010; Ray and Li 2013; Ogata and Aiki 2020). Section 4c has depicted the significant intraseasonal signals in tropics connected with these two types of mid-high-latitude LF-ISOs. Here, we attempt to understand the coherent tropical atmospheric intraseasonal variations found in section $4 \mathrm{c}$. For both types of LF-ISO wave 
(a) $\mathrm{U}_{250}\left(\mathrm{NAO}^{+}\right.$- $\left.\mathrm{NAO}^{-}\right)$

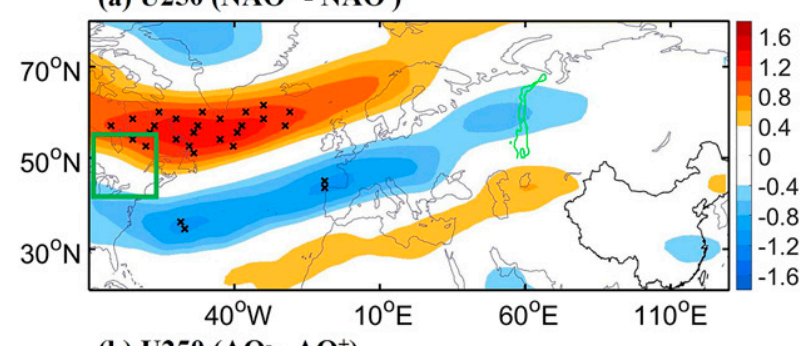

(b) $\mathrm{U}^{250}\left(\mathrm{AO}^{-}-\mathrm{AO}^{+}\right)$

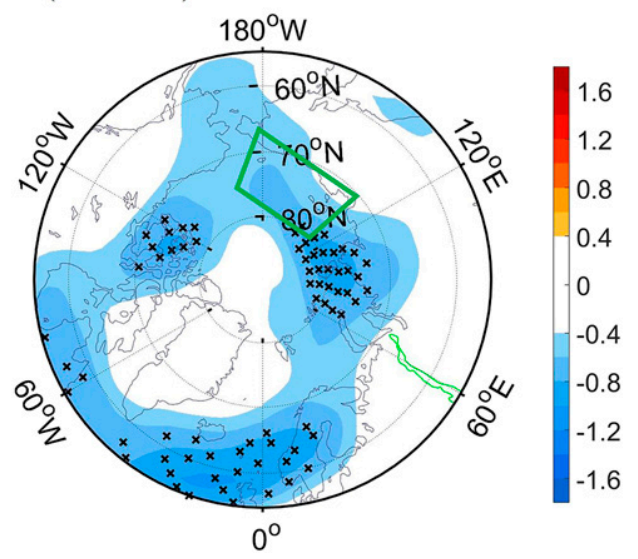

FIG. 13. Composite difference of 250-hPa zonal wind (U250; $\mathrm{m} \mathrm{s}^{-1}$ ) between the (a) positive and negative phases of the NAO and (b) negative and positive phases of the AO. The green rectangle is the E-Source in (a) and W-Source in (b), and the green lines represent the UM. The black X marks show the results above the $95 \%$ confidence level.

trains, we find that the upper-level anomalous divergence (convergence) accompanied with an enhanced (suppressed) convection over the Arabian Sea and Indian Peninsula always occurs to the south of the anomalous high (low) pressure over central Asia. And this tropical-extratropical connection can be interpreted from two aspects. The first is the role of the easterly vertical shear. Taking the phase 1 in Fig. 9 as the example, the upper-troposphere easterly anomalies to the south of the central Asian high anomaly enhance the easterly vertical shear. According to Wang and Xie (1996), the moist Rossby wave instability is enhanced by the easterly vertical shear in the presence of the boundary layer. Meanwhile, the enhanced easterly vertical shear can reinforce the meridional heat flux, which favors the available potential conversion from the mean flow to eddy (Ding and Wang 2007). Both effects are conducive to the enhanced convection over the Arabian Sea and Indian Peninsula. The second possible interpretation is that, also taking the phase 1 in Fig. 9 as the example, there are strengthened anomalous easterly winds to the south of the central Asian anomalous high (i.e., $d u_{g} / d t<0$, where $u_{g}$ is the geostrophic component of zonal winds). According to the quasigeostrophic version of the zonal momentum equation (Hoskins and Wang 2006), there must be a northerly ageostrophic flow, and consequently generating the upper-level divergence over the south of the central Asian anomalous high.
However, the mechanism for the coherent intraseasonal variations over the tropical western Pacific remains unclear and is ready to be explored. Meanwhile, we notice a Pacific-North American pattern (PNA)-like wave pattern occurring over the Pacific, which is linked with the Maritime Continent convective anomaly in the westward propagating mode. Some previous studies have reported that the PNA-like pattern can be caused by tropical western Pacific convection, as a Rossby wave energy pathway, which connects the tropics and mid-high latitudes on multiple time scales (e.g., Huang 1985; Riddle et al. 2013; Henderson et al. 2016; Chu et al. 2018). Some research studies have also found that the PNA pattern induced by tropical western Pacific convection contributes to the occurrence of European blocking (Hamill and Kiladis 2014), which indicates that the tropical anomalous convection may influence or generate mid-high-latitude ISO.

\section{Summary}

Based on daily circulation reanalysis data during 1982-2018, two types of mid-high-latitude intraseasonal wave trains, characterized by eastward and westward propagation, are identified over the Eurasian continent during boreal summer. Both of these two distinct types commonly have significant signals over the west of the UM region, with a dominant spectrum peak of 30-50 days, and feature barotropic vertical structures. However, their origins and evolutions differ. The eastward propagating mid-high-latitude LF-ISO wave train occurs mainly along the latitudes between $40^{\circ}$ and $60^{\circ} \mathrm{N}$. It initiates over eastern North America, moves northeastward across northeastern North America/western North Atlantic, central North Atlantic, and western Europe, enhances its amplitude near the UM, and continuously migrates eastward across the UM. Afterward, the eastward propagating intraseasonal wave train moves southeastward to northwestern China and eventually reaches eastern China. In contrast, the pathway of the westward propagating mid-high-latitude LF-ISO wave train is quasi-circumpolar and locates in higher latitudes between $60^{\circ}$ and $80^{\circ} \mathrm{N}$. It initiates over the East Siberian Sea, moves southwestward and enhances near the UM, and then moves westward to northern Europe, eventually reaching Greenland and the Canadian Arctic Archipelago. The two types of mid-high-latitude LF-ISOs also have significant footprints on the tropical regions, indicating the evident tropical-extratropical interactions. We summarize the two types of wave trains and their footprints over the tropics in the schematic diagram shown in Fig. 14. Meanwhile, remarkable decadal preferences of these two LF-ISOs are identified: eastward propagating events preferentially occur in the pre-2000 epoch and westward propagating events favor the post-2000 epoch. This decadal change is associated with the change of intraseasonal efficient kinetic energy obtained from the mean flow over their respective perturbation source areas, as well as the change of their background flow caused by the NAO/AO decadal shift. The detection of the dominant mid-high-latitude LF-ISOs indicates that we can build up a mid-high-latitude matrix to describe the extratropical LFISO and eventually help to improve downstream regional subseasonal prediction. 
(a) Eastward propagating LF-ISO

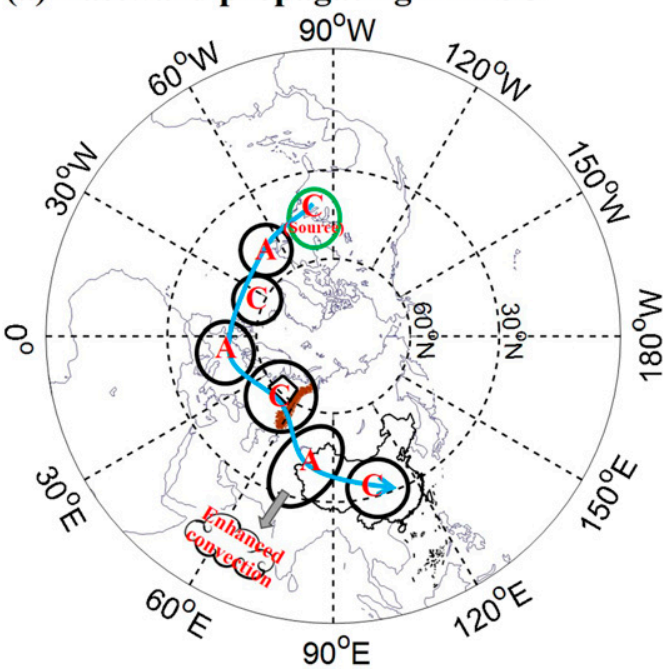

(b) Westward propagating LF-ISO

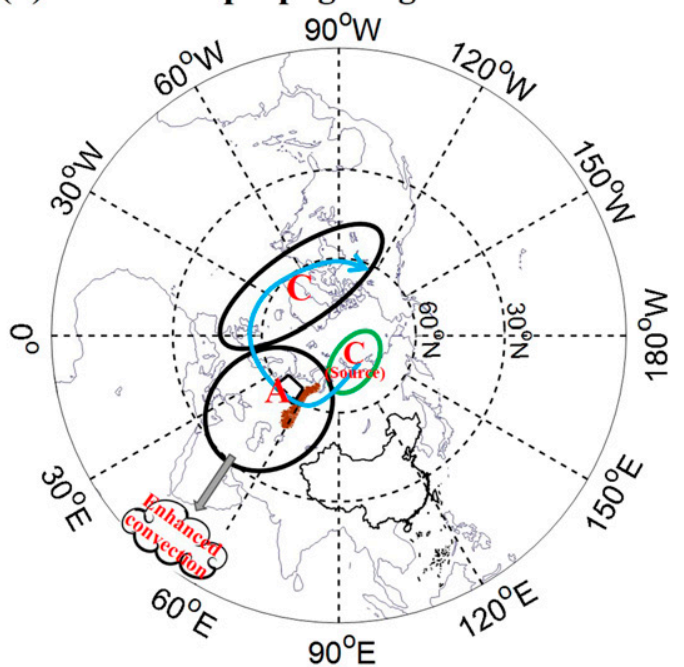

FIG. 14. Schematic diagram of the two distinct propagating LF-ISO wave trains, summarizing the transient wave trains and propagating paths in the upper troposphere. Letters " $\mathrm{A}$ " and " $\mathrm{C}$ " denote the center of anticyclonic and cyclonic anomaly along the wave train propagation paths, respectively. The green circles are the source regions. The blue arrows show the propagating direction. The cloud shape denotes enhanced convection. The brown lines represent the UM, and the black rectangles show the UM core region of this study.

Acknowledgments. This research was supported by funds from the National Key Program for Developing Basic Science (Grant 2018YFC1505903), and the National Natural Science Foundation of China (Grants 42022034 and 41775071). The authors appreciate Professor Xiuqun Yang and Professor Jiabei Fang at Nanjing University for their helpful comments, and three anonymous referees for their in-depth comments and constructive suggestions. The authors thank the high-performance computing support from the Center for Geodata and Analysis, Faculty of Geographical Science, Beijing Normal University.

\section{REFERENCES}

Batstone, C., and H. H. Hendon, 2005: Characteristics of stochastic variability associated with ENSO and the role of the MJO. J. Climate, 18, 1773-1789, https://doi.org/10.1175/JCLI3374.1.

Bingham, C., M. Godfrey, and J. Tukey, 1967: Modern techniques of power spectrum estimation. IEEE Trans. Audio Electroacoust., 15, 56-66, https://doi.org/10.1109/TAU.1967.1161895.

Bloomfield, P., 2000: Fourier Analysis of Time Series: An Introduction. 2nd ed. Wiley, $261 \mathrm{pp}$.

Branstator, G., 1987: A striking example of the atmosphere's leading traveling pattern. J. Atmos. Sci., 44, 2310-2323, https://doi.org/ 10.1175/1520-0469(1987)044<2310:ASEOTA >2.0.CO;2.

Bretherton, C. S., M. Widmann, V. P. Dymnikov, J. M. Wallace, and I. Bladé, 1999: The effective number of spatial degrees of freedom of a time-varying field. J. Climate, 12, 1990-2009, https://doi.org/ 10.1175/1520-0442(1999)012<1990:TENOSD>2.0.CO;2.

Chan, J., W. Wi, and J. Xu, 2002: Mechanisms responsible for the maintenance of the 1998 South China Sea summer monsoon. J. Meteor. Soc. Japan, 80, 1103-1113, https://doi.org/10.2151/jmsj.80.1103.

Chen, S., R. Wu, W. Chen, K. Hu, and B. Yu, 2020: Structure and dynamics of a springtime atmospheric wave train over the North Atlantic and Eurasia. Climate Dyn., 54, 5111-5126, https://doi.org/10.1007/s00382-020-05274-7.
Chen, T. C., and M. C. Yen, 1991: Interaction between intraseasonal oscillations of the midlatitude flow and tropical convection during 1979 northern summer: The Pacific Ocean. J. Climate, 4, 653-671, https://doi.org/10.1175/1520-0442(1991) 004<0653:IBIOOT >2.0.CO;2.

Chu, C., X. Yang, X. Sun, D. Yang, Y. Jiang, T. Feng, and J. Liang, 2018: Effect of the tropical Pacific and Indian Ocean warming since the late 1970s on wintertime Northern Hemispheric atmospheric circulation and East Asian climate interdecadal changes. Climate Dyn., 50, 3031-3048, https://doi.org/10.1007/ s00382-017-3790-y.

Cui, J., S. Yang, and T. Li, 2020: The influence of the MaddenJulian oscillation on high-latitude surface air temperature during boreal winter. Dyn. Atmos. Oceans, 90, 101141, https:// doi.org/10.1016/j.dynatmoce.2020.101141.

Delworth, T. L., F. Zeng, G. A. Vecchi, X. Yang, L. Zhang, and R. Zhang, 2016: The North Atlantic Oscillation as a driver of rapid climate change in the Northern Hemisphere. Nat. Geosci., 9, 509-512, https://doi.org/10.1038/ngeo2738.

Dickey, J. O., M. Ghil, and S. Marcus, 1991: Extratropical aspects of the 40-50 day oscillation in length-of-day and atmospheric angular momentum. J. Geophys. Res., 96, 22 643-22 658, https://doi.org/10.1029/91JD02339.

Ding, Q., and B. Wang, 2007: Intraseasonal teleconnection between the summer Eurasian wave train and the Indian monsoon. J. Climate, 20, 3751-3767, https://doi.org/10.1175/ JCLI4221.1.

Ferranti, L., T. N. Palmer, F. Molteni, and E. Klinker, 1990: Tropical-extratropical interaction associated with the 3060 day oscillation and its impact on medium and extended range prediction. J. Atmos. Sci., 47, 2177-2199, https://doi.org/ 10.1175/1520-0469(1990)047<2177:TEIAWT>2.0.CO;2.

Fujinami, H., and T. Yasunari, 2004: Submonthly variability of convection and circulation over and around the Tibetan Plateau during the boreal summer. J. Meteor. Soc. Japan, 82, 1545-1564, https://doi.org/10.2151/jmsj.82.1545. 
Gao, M., J. Yang, B. Wang, S. Zhou, and S. J. Kim, 2017: How are heat waves over Yangtze River valley associated with atmospheric quasi-biweekly oscillation? Climate Dyn., 51, 44214437, https://doi.org/10.1007/S00382-017-3526-Z.

Ghil, M., and K. Mo, 1991: Intraseasonal oscillations in the global atmosphere. Part I: Northern Hemisphere and tropics. J. Atmos. Sci., 48, 780-790, https://doi.org/10.1175/1520-0469(1991)048<0780: IOITGA $>2.0 . \mathrm{CO} ; 2$.

Hall, N. M. J., S. Thibaut, and P. Marchesiello, 2017: Impact of the observed extratropics on climatological simulations of the MJO in a tropical channel model. Climate Dyn., 48, 25412555, https://doi.org/10.1007/s00382-016-3221-5.

Hamill, T. M., and G. N. Kiladis, 2014: Skill of the MJO and Northern Hemisphere blocking in GEFS medium-range reforecasts. Mon. Wea. Rev., 142, 868-885, https://doi.org/ 10.1175/MWR-D-13-00199.1.

He, J., and S. Yang, 1992: Meridional propagation of East Asia lowfrequency mode and midlatitude low-frequency waves. Acta Meteor. Sin., 50, 190-198.

Henderson, S. A., E. D. Maloney, and E. A. Barnes, 2016: The influence of the Madden-Julian oscillation on Northern Hemisphere winter blocking. J. Climate, 29, 4597-4616, https://doi.org/10.1175/JCLI-D-15-0502.1.

Hoskins, B. J., and G. Y. Yang, 2000: The equatorial response to higher-latitude forcing. J. Atmos. Sci., 57, 1197-1213, https:// doi.org/10.1175/1520-0469(2000)057<1197:TERTHL>2.0.CO;2.

_ , and B. Wang, 2006: Large-scale atmospheric dynamics. The Asian Monsoon. B. Wang, Ed., Springer, 357-415.

— I. N. James, and G. H. White, 1983: The shape, propagation and mean-flow interaction of large-scale weather systems. J. Atmos. Sci., 40, 1595-1612, https://doi.org/10.1175/15200469(1983)040<1595:TSPAMF>2.0.CO;2.

Hu, W., A. Duan, Y. Li, and B. He, 2016: The intraseasonal oscillation of eastern Tibetan Plateau precipitation in response to the summer Eurasian wave train. J. Climate, 29, 7215-7230, https://doi.org/10.1175/JCLI-D-15-0620.1.

Huang, R., 1985: The effect of heating anomaly over low latitudes on the circulation anomalies in the northern hemisphere winter troposphere. Acta Meteor. Sin., 43, 410-423.

Jin, F., and M. Ghil, 1990: Intraseasonal oscillations in the extratropics: Hopf bifurcation and topographic instabilities. J. Atmos. Sci., 47, 3007-3022, https://doi.org/10.1175/1520-0469(1990) 047<3007:IOITEH > 2.0.CO;2.

Jones, C., D. E. Waliser, K. M. Lau, and W. Stern, 2004: Global occurrences of extreme precipitation and the Madden-Julian oscillation: Observations and predictability. J. Climate, 17, 4575-4589, https://doi.org/10.1175/3238.1.

Kalnay, E., and Coauthors, 1996: The NCEP/NCAR 40-Year Reanalysis project. Bull. Amer. Meteor. Soc., 74, 789-799, https://doi.org/10.1175/1520-0477(1996)077<0437:TNYRP> 2.0.CO;2.

Kawamura, R., T. Murakami, and B. Wang, 1996: Tropical and mid-latitude 45-day perturbations over the western Pacific during the northern summer. J. Meteor. Soc. Japan, 74, 867890, https://doi.org/10.2151/jmsj1965.74.6_867.

Kikuchi, K., and B. Wang, 2009: Global perspective of the quasibiweekly oscillation. J. Climate, 22, 1340-1359, https://doi.org/ 10.1175/2008JCLI2368.1.

Krishnamurti, T., and S. Gadgil, 1985: On the structure of the 30 to 50 day mode over the globe during FGGE. Tellus, 37, 336-360, https://doi.org/10.3402/tellusa.v37i4.11677.

Lau, K.-H., and N.-C. Lau, 1990: Observed structure and propagation characteristics of tropical summertime synoptic scale disturbances. Mon. Wea. Rev., 118, 1888-1913, https://doi.org/ 10.1175/1520-0493(1990)118<1888:OSAPCO > 2.0.CO;2.

Lau, K. M., and P. H. Chan, 1986: Aspects of the 40-50 day oscillation during the northern winter as inferred from outgoing longwave radiation. Mon. Wea. Rev., 114, 1354-1367, https://doi.org/ 10.1175/1520-0493(1986)114<1354:AOTDOD>2.0.CO;2.

_ , and T. J. Phillips, 1986: Coherent fluctuations of extratropical geopotential height and tropical convection in intraseasonal time scales. J. Atmos. Sci., 43, 1164-1181, https://doi.org/ 10.1175/1520-0469(1986)043<1164:CFOFGH>2.0.CO;2.

Lee, J. Y., B. Wang, M. C. Wheeler, X. Fu, D. E. Waliser, and S. Kang, 2013: Real-time multivariate indices for the boreal summer intraseasonal oscillation over the Asian summer monsoon region. Climate Dyn., 40, 493-509, https://doi.org/ 10.1007/s00382-012-1544-4.

Li, C., 1991: Global characteristics of 30-60 day atmospheric oscillation (in Chinese). Chin, J. Atmos. Sci., 15, 66-76.

Li, J., C. Sun, and F. F. Jin, 2013: NAO implicated as a predictor of Northern Hemisphere mean temperature multidecadal variability. Geophys. Res. Lett., 40, 5497-5502, https://doi.org/ 10.1002/2013GL057877.

Liebmann, B., and C. A. Smith, 1996: Description of a complete (interpolated) outgoing longwave radiation dataset. Bull. Amer. Meteor. Soc., 77, 1275-1277.

Lin, H., G. Brunet, and J. Derome, 2007: Intraseasonal variability in a dry atmospheric model. J. Atmos. Sci., 64, 2422-2441, https://doi.org/10.1175/JAS3955.1.

Lin, W. B., J. D. Neelin, and N. Zeng, 2000: Maintenance of tropical intraseasonal variability: Impact of evaporation-wind feedback and midlatitude storms. J. Atmos. Sci., 57, 27932823, https://doi.org/10.1175/1520-0469(2000)057<2793: MOTIVI>2.0.CO;2.

Liu, B., Y. Yan, C. Zhu, S. Ma, and J. Li, 2020: Record-breaking Meiyu rainfall around the Yangtze River in 2020 regulated by the subseasonal phase transition of the North Atlantic Oscillation. Geophys. Res. Lett., 47, e2020GL090342, https:// doi.org/10.1029/2020GL090342.

Liu, H., Y. Yang, D. L. Zhang, and B. Wang, 2014: Roles of synoptic to quasi-biweekly disturbances in generating the summer 2003 heavy rainfall in East China. Mon. Wea. Rev., 142, 886904, https://doi.org/10.1175/MWR-D-13-00055.1.

Liu, P., Y. Zhu, Q. Zhang, J. Gottschalck, M. Zhang, and C. Melhauser, 2018: Climatology of tracked persistent maxima of 500-hPa geopotential height. Climate Dyn., 51, 701-717, https://doi.org/10.1007/s00382-017-3950-0.

Lott, F., A. W. Robertson, and M. Ghil, 2001: Mountain torques and atmospheric oscillations. Geophys. Res. Lett., 28, 12071210, https://doi.org/10.1029/2000GL011829.

,-- , and,- 2004 : Mountain torques and Northern Hemisphere low-frequency variability. Part I: Hemispheric aspects. J. Atmos. Sci., 61, 1259-1271, https://doi.org/10.1175/ 1520-0469(2004)061<1259:MTANHL>2.0.CO;2.

Lybarger, N. D., and C. Stan, 2019: Revisiting MJO, Kelvin waves, and El Niño relationships using a simple ocean model. Climate Dyn., 53, 6363-6377, https://doi.org/10.1007/s00382-019-04936-5.

Madden, R. A., and P. R. Julian, 1971: Detection of a 40-50 day oscillation in the zonal wind in the tropical Pacific. J. Atmos. Sci., 28, 702-708, https://doi.org/10.1175/1520-0469(1971)028<0702: DOADOI $>2.0 . \mathrm{CO} ; 2$.

_ , and - 1972: Description of global-scale circulation cells in the tropics with a 40-50 day period. J. Atmos. Sci., 29, 1109-1123, https://doi.org/10.1175/1520-0469(1972)029<1109:DOGSCC > 2.0. $\mathrm{CO} ; 2$. 
Mao, J., and J. C. L. Chan, 2005: Intraseasonal variability of the South China Sea summer monsoon. J. Climate, 18, 2388-2402, https://doi.org/10.1175/JCLI3395.1.

Nitta, T., 1983: Observational study of heat sources over the eastern Tibetan Plateau during the summer monsoon. J. Meteor. Soc. Japan, 61, 590-605, https://doi.org/10.2151/jmsj1965.61.4_ 590.

Ogata, T., and H. Aiki, 2020: The pathway of intraseasonal wave energy in the tropical Indian Ocean as identified by a seamless diagnostic scheme. SOLA, 2019, 262-267, https://doi.org/ 10.2151/SOLA.2019-047.

Qi, X., and J. Yang, 2019: Extended-range prediction of a heat wave event over the Yangtze River valley: Role of intraseasonal signals. Atmos. Oceanic Sci. Lett., 12, 451-457, https:// doi.org/10.1080/16742834.2019.1669408.

,$- \ldots$, M. Gao, H. Yang, and H. Liu, 2019: Roles of the tropical/extratropical intraseasonal oscillations on generating the heat wave over Yangtze River Valley: A numerical study. J. Geophys. Res. Atmos., 124, 3110-3123, https://doi.org/ 10.1029/2018JD029868.

Qian, S., L. Zhang, B. Yang, A. Huang, and Y. Zhang, 2020: Analysis of intraseasonal oscillation characteristics of Arctic summer sea ice. Geophys. Res. Lett., 47, e2019GL086555, https://doi.org/10.1029/2019GL086555.

Qian, X., J. Yu, and C. Wang, 2018: Effects of intraseasonal oscillation of East Asian zonal wind on tropical cyclone landfall in the mainland of China during boreal summer (in Chinese). J. Trop. Meteor., 34, 705-712.

Ray, P., and C. Zhang, 2010: A case study of the mechanics of extratropical influence on the initiation of the Madden-Julian oscillation. J. Atmos. Sci., 67, 515-528, https://doi.org/10.1175/ 2009JAS3059.1.

— extratropics on the MJO and its relationship with the mean state. J. Atmos. Sci., 70, 876-893, https://doi.org/10.1175/JASD-12-0153.1.

Recalde-Coronel, C., B. Zaitchik, and W. Pan, 2020: MaddenJulian Oscillation influence on sub-seasonal rainfall variability on the west of South America. Climate Dyn., 54, 2167-2185, https://doi.org/10.1007/s00382-019-05107-2.

Riddle, E., M. Stoner, N. Johnson, M. L'Heureux, D. Collins, and S. Feldstein, 2013: The impact of the MJO on clusters of wintertime circulation anomalies over the North American region. Climate Dyn., 40, 1749-1766, https://doi.org/10.1007/ s00382-012-1493-y.

Sardeshmukh, P., and B. Hoskins, 1988: The generation of global rotational flow by steady idealized tropical divergence. J. Atmos. Sci., 45, 1228-1251, https://doi.org/10.1175/1520-0469(1988) $045<1228$ :TGOGRF $>2.0 . \mathrm{CO} ; 2$.

Seo, K., and H. Lee, 2017: Mechanisms for a PNA-like teleconnection pattern in response to the MJO. J. Atmos. Sci., 74, 1767-1781, https://doi.org/10.1175/JAS-D-16-0343.1.

Simmons, A., J. Wallace, and G. Branstator, 1983: Barotropic wave propagation and instability, and atmospheric teleconnection patterns. J. Atmos. Sci., 40, 1363-1392, https://doi.org/10.1175/ 1520-0469(1983)040<1363:BWPAIA > 2.0.CO;2.

— S. Uppala, D. Dee, and S. Kobayashi, 2006: ERA-Interim: New ECMWF reanalysis products from 1989 onwards. ECMWF Newsletter, No. 110, 25-35, https://www.ecmwf.int/ sites/default/files/elibrary/2006/14615-newsletter-no110-winter200607.pdf

Sperber, K., 2003: Propagation and the vertical structure of the Madden-Julian oscillation. Mon. Wea. Rev., 131, 3018-
3037, https://doi.org/10.1175/1520-0493(2003)131<3018: PATVSO $>2.0 . \mathrm{CO} ; 2$.

Stan, C., D. Straus, J. Frederiksen, H. Lin, E. Maloney, and C. Schumacher, 2017: Review of tropical-extratropical teleconnections on intraseasonal time scales. Rev. Geophys., 55, 902-937, https://doi.org/10.1002/2016RG000538.

Takaya, K., and H. Nakamura, 2001: A formulation of a phaseindependent wave-activity flux for stationary and migratory quasi-geostrophic eddies on a zonally varying basic flow. J. Atmos. Sci., 58, 608-627, https://doi.org/10.1175/15200469(2001)058<0608:AFOAPI > 2.0.CO;2.

Teng, H., G. Branstator, H. Wang, G. Meehl, and W. Washington, 2013: Probability of us heat waves affected by a subseasonal planetary wave pattern. Nat. Geosci., 6, 1056-1061, https:// doi.org/10.1038/ngeo1988.

Torrence, C., and G. Compo, 1998: A practical guide to wavelet analysis. Bull. Amer. Meteor. Soc., 79, 61-78, https://doi.org/ 10.1175/1520-0477(1998)079<0061:APGTWA > 2.0.CO;2.

Tseng, K., E. Maloney, and E. Barnes, 2019: The consistency of MJO teleconnection patterns: An explanation using linear Rossby wave theory. J. Climate, 32, 531-548, https://doi.org/ 10.1175/JCLI-D-18-0211.1.

Wang, B., and H. Rui, 1990: Synoptic climatology of transient tropical intraseasonal convection anomalies: 1975-1985. Meteor. Atmos. Phys., 44, 43-61, https://doi.org/10.1007/BF01026810.

- and X. Xie, 1996: Low-frequency equatorial waves in vertically sheared zonal flow. Part I: Stable waves. J. Atmos. Sci., 53, 449467, https://doi.org/10.1175/1520-0469(1996)053<0449: LFEWIV $>2.0 . \mathrm{CO} ; 2$.

Wang, L., T. Li, T. Zhou, and X. Rong, 2013: Origin of the intraseasonal variability over the North Pacific in boreal summer. J. Climate, 26, 1211-1229, https://doi.org/10.1175/JCLI-D-1100704.1.

Watanabe, T., and K. Yamazaki, 2014: The upper-level circulation anomaly over central Asia and its relationship to the Asian monsoon and mid-latitude wave train in early summer. Climate Dyn., 42, 2477-2489, https://doi.org/10.1007/s00382-013-1888-4.

Wheeler, M., and H. Hendon, 2004: An all-season real-time multivariate MJO index: Development of an index for monitoring and prediction. Mon. Wea. Rev., 132, 1917-1932, https://doi.org/ 10.1175/1520-0493(2004)132<1917:AARMMI>2.0.CO;2.

- _ - S. Cleland, H. Meinke, and A. Donald, 2009: Impacts of the Madden-Julian oscillation on Australian rainfall and circulation. J. Climate, 22, 1482-1498, https://doi.org/10.1175/ 2008JCLI2595.1.

Xavier, P., and Coauthors, 2020: Seasonal dependence of cold surges and their interaction with the Madden-Julian oscillation over Southeast Asia. J. Climate, 33, 2467-2482, https:// doi.org/10.1175/JCLI-D-19-0048.1.

Xie, X., and B. Wang, 1996: Low-frequency equatorial waves in vertically sheared zonal flow. Part II: Unstable waves. J. Atmos. Sci., 53, 3589-3605, https://doi.org/10.1175/1520-0469(1996)053<3589: LFEWIV $>2.0 . \mathrm{CO} ; 2$.

Yamada, H., and H. Uyeda, 2006: Transition of the rainfall characteristics related to the moistening of the land surface over the central Tibetan Plateau during the summer of 1998. Mon. Wea. Rev., 134, 3230-3247, https://doi.org/10.1175/ MWR3235.1.

Yang, D., and W. Cao, 1995: A possible dynamic mechanism of the atmospheric 30-60 day period oscillation in the extratropical latitude (in Chinese). Chin. J. Atmos. Sci., 19, 209-218.

Yang, H., and C. Li, 2003: The relation between atmospheric intraseasonal oscillation and summer severe flood and drought 
in the Changjiang-Huaihe River basin. Adv. Atmos. Sci., 20, 540-553, https://doi.org/10.1007/BF02915497.

Yang, J., and R. Wu, 2019: Propagation and influence on tropical precipitation of intraseasonal variation over mid-latitude East Asia in boreal winter. Atmos. Oceanic Sci. Lett., 12, 155-161, https://doi.org/10.1080/16742834.2019.1586518.

_ B. Bang, and Q. Bao, 2010: Biweekly and 21-30-day variations of the subtropical summer monsoon rainfall over the lower reach of the Yangtze River basin. J. Climate, 23, 11461159, https://doi.org/10.1175/2009JCLI3005.1.

_, Q. Bao, B. Wang, D. Y. Gong, H. He, and M. N. Gao, 2014: Distinct quasi-biweekly features of the subtropical East Asian monsoon during early and late summers. Climate Dyn., 42, 1469-1486, https://doi.org/10.1007/s00382-013-1728-6.

,,,--- H. He, M. Gao, and D. Gong, 2017: Characterizing two types of transient intraseasonal oscillations in the eastern Tibetan Plateau summer rainfall. Climate Dyn., 48, 1749-1768, https://doi.org/10.1007/s00382-016-3170-z.

Yang, S., and T. Li, 2016: Intraseasonal variability of air temperature over the mid-high latitude Eurasia in boreal winter. Climate Dyn., 47, 2155-2175, https://doi.org/10.1007/s00382-015-2956-8.

, B. Wu, S. Zhou, and W. Liu, 2012: Progress in researches on atmospheric intraseasonal oscillation. Mater. Sci. Technol., 40, 938-948.
—_ _ _ R. Zhang, and S. Zhou, 2013: Relationship between an abrupt drought-flood transition over mid-low reaches of the Yangtze River in 2011 and the intraseasonal oscillation over mid-high latitudes of East Asia. Acta Meteor. Sin., 27, 129-143, https://doi.org/10.1007/s13351-013-0201-0.

— Z Z. Zhu, J. Cui, and Y. Yang, 2019: Regulation of the intraseasonal oscillation over mid-to-high latitude Eurasia on winter surface air temperature over China. Dyn. Atmos. Oceans, 86, 63-72, https://doi.org/10.1016/j.dynatmoce.2019.03.003.

Zangvil, A., and M. Yanai, 1980: Upper tropospheric waves in the tropics. Part I: Dynamical analysis in the wavenumber-frequency domain. J. Atmos. Sci., 37, 283-298, https://doi.org/10.1175/15200469(1980)037<0283:UTWITT>2.0.CO;2.

Zhang, C., 2013: Madden-Julian oscillation: Bridging weather and climate. Bull. Amer. Meteor. Soc., 94, 1849-1870, https:// doi.org/10.1175/BAMS-D-12-00026.1.

Zhao, W., W. Chen, S. Chen, D. Nath, and L. Wang, 2020: Interdecadal change in the impact of North Atlantic SST on August rainfall over the monsoon transitional belt in China around the late 1990s. Theor. Appl. Climatol., 140, 503-516, https://doi.org/10.1007/s00704-020-03102-w.

Zhu, Z., and T. Li, 2018: Extended-range forecasting of Chinese summer surface air temperature and heat waves. Climate Dyn., 50, 2007-2021, https://doi.org/10.1007/S00382-017-3733-7. 